\title{
Multi-model study of mercury dispersion in the atmosphere: atmospheric processes and model evaluation
}

Oleg Travnikov $^{1}$, Hélène Angot ${ }^{2, a}$, Paulo Artaxo ${ }^{3}$, Mariantonia Bencardino ${ }^{4}$, Johannes Bieser ${ }^{5}$, Francesco D’Amore $^{4}$, Ashu Dastoor ${ }^{6}$, Francesco De Simone ${ }^{4}$, María del Carmen Diéguez ${ }^{7}$, Aurélien Dommergue ${ }^{2,8}$, Ralf Ebinghaus ${ }^{5}$, Xin Bin Feng ${ }^{9}$, Christian N. Gencarelli ${ }^{4}$, Ian M. Hedgecock ${ }^{4}$, Olivier Magand ${ }^{8}$, Lynwill Martin $^{10}$, Volker Matthias $^{5}$, Nikolay Mashyanov ${ }^{11}$, Nicola Pirrone ${ }^{12}$, Ramesh Ramachandran ${ }^{13}$, Katie Alana Read ${ }^{14}$, Andrei Ryjkov ${ }^{6}$, Noelle E. Selin ${ }^{15,16}$, Fabrizio Sena ${ }^{17}$, Shaojie Song ${ }^{15}$, Francesca Sprovieri ${ }^{4}$, Dennis Wip ${ }^{18}$, Ingvar Wängberg ${ }^{19}$, and Xin Yang ${ }^{20}$

${ }^{1}$ Meteorological Synthesizing Centre - East of EMEP, Moscow, Russia

${ }^{2}$ University Grenoble Alpes, CNRS, IRD, IGE, Grenoble, France

${ }^{3}$ University of Sao Paulo, Sao Paulo, Brazil

${ }^{4}$ CNR Institute of Atmospheric Pollution Research, Rende, Italy

${ }^{5}$ Institute of Coastal Research, Helmholtz-Zentrum Geesthacht, Geesthacht, Germany

${ }^{6}$ Air Quality Research Division, Environment and Climate Change Canada, Dorval, Québec, Canada

${ }^{7}$ INIBIOMA-CONICET-UNComa, Bariloche, Argentina

${ }^{8} \mathrm{CNRS}$, Laboratoire de Glaciologie et Géophysique de l'Environnement, Grenoble, France

${ }^{9}$ Institute of Geochemistry, State Key Laboratory of Environmental Geochemistry, Chinese Academy of Sciences, Guiyang, China

${ }^{10}$ Cape Point GAW Station, Climate and Environment Research \& Monitoring, South African Weather Service,

Stellenbosch, South Africa

${ }^{11}$ St. Petersburg State University, St. Petersburg, Russia

${ }^{12} \mathrm{CNR}$ Institute of Atmospheric Pollution Research, Rome, Italy

${ }^{13}$ Institute for Ocean Management, Anna University, Chennai, India

${ }^{14}$ NCAS, University of York, York, UK

${ }^{15}$ Department of Earth, Atmospheric and Planetary Sciences, Massachusetts Institute of Technology, Cambridge, MA, USA

${ }^{16}$ Institute for Data, Systems, and Society, Massachusetts Institute of Technology, Cambridge, MA, USA

${ }^{17}$ Joint Research Centre, Ispra, Italy

${ }^{18}$ Department of Physics, University of Suriname, Paramaribo, Suriname

${ }^{19}$ IVL Swedish Environmental Research Institute, Göteborg, Sweden

${ }^{20}$ British Antarctic Survey, Cambridge, UK

${ }^{a}$ now at: Institute for Data, Systems and Society, Massachusetts Institute of Technology, Cambridge, MA, USA

Correspondence to: Oleg Travnikov (oleg.travnikov@msceast.org)

Received: 14 October 2016 - Discussion started: 31 October 2016

Revised: 3 March 2017 - Accepted: 14 March 2017 - Published: 24 April 2017 
Abstract. Current understanding of mercury ( $\mathrm{Hg}$ ) behavior in the atmosphere contains significant gaps. Some key characteristics of $\mathrm{Hg}$ processes, including anthropogenic and geogenic emissions, atmospheric chemistry, and air-surface exchange, are still poorly known. This study provides a complex analysis of processes governing $\mathrm{Hg}$ fate in the atmosphere involving both measured data from ground-based sites and simulation results from chemical transport models. A variety of long-term measurements of gaseous elemental $\mathrm{Hg}(\mathrm{GEM})$ and reactive $\mathrm{Hg}(\mathrm{RM})$ concentration as well as $\mathrm{Hg}$ wet deposition flux have been compiled from different global and regional monitoring networks. Four contemporary global-scale transport models for $\mathrm{Hg}$ were used, both in their state-of-the-art configurations and for a number of numerical experiments to evaluate particular processes. Results of the model simulations were evaluated against measurements. As follows from the analysis, the interhemispheric GEM gradient is largely formed by the prevailing spatial distribution of anthropogenic emissions in the Northern Hemisphere. The contributions of natural and secondary emissions enhance the south-to-north gradient, but their effect is less significant. Atmospheric chemistry has a limited effect on the spatial distribution and temporal variation of GEM concentration in surface air. In contrast, RM air concentration and wet deposition are largely defined by oxidation chemistry. The $\mathrm{Br}$ oxidation mechanism can reproduce successfully the observed seasonal variation of the RM / GEM ratio in the near-surface layer, but it predicts a wet deposition maximum in spring instead of in summer as observed at monitoring sites in North America and Europe. Model runs with $\mathrm{OH}$ chemistry correctly simulate both the periods of maximum and minimum values and the amplitude of observed seasonal variation but shift the maximum RM / GEM ratios from spring to summer. $\mathrm{O}_{3}$ chemistry does not predict significant seasonal variation of $\mathrm{Hg}$ oxidation. Hence, the performance of the $\mathrm{Hg}$ oxidation mechanisms under study differs in the extent to which they can reproduce the various observed parameters. This variation implies possibility of more complex chemistry and multiple $\mathrm{Hg}$ oxidation pathways occurring concurrently in various parts of the atmosphere.

\section{Introduction}

Mercury $(\mathrm{Hg})$ is widely recognized as a toxic pollutant that is capable of long-range transport, bioaccumulation in ecosystems and biota, and adverse effects on human health and the environment. Although it is a natural element, its concentrations in the environment have been considerably enriched by human activities since pre-industrial times (Fitzgerald et al., 1998; Mason and and Sheu, 2002; Krabbenhoft and Sunderland, 2013). Once emitted to the atmosphere, $\mathrm{Hg}$ can be dispersed globally, impacting remote regions through deposition to aquatic ecosystems, transformation to a potent neu- rotoxic form (methylmercury), and bioaccumulation in food chains (Mahaffey et al., 2004; Sunderland et al., 2010; Mason et al., 2012). The character of $\mathrm{Hg}$ transport and fate in the atmosphere is largely determined by the properties of its various chemical forms. Mercury is emitted into the atmosphere from anthropogenic sources in the form of both gaseous elemental mercury (GEM) and oxidized Hg chemical compounds (Pirrone et al., 2010). The latter are typically divided into two operationally defined forms: gaseous oxidized mercury (GOM) and particle-bound mercury (PBM). In addition, GEM can also originate from natural geogenic and secondary sources (Mason, 2009). Reactive mercury ( $\mathrm{RM}=\mathrm{GOM}+$ PBM) can also be produced in the atmosphere from gasand aqueous-phase oxidation of GEM (Lindberg and Stratton, 1998). Relatively stable and slightly soluble GEM can drift in the atmosphere for months, providing transport of Hg mass around the globe (Schroeder and Munthe, 1998). In contrast, RM is easily removed from the air by precipitation scavenging (wet deposition) or surface uptake (dry deposition) (Schroeder and Munthe, 1998; Gustin et al., 2012; Sather et al., 2013; Wright et al., 2014). GEM can also contribute to $\mathrm{Hg}$ dry deposition through air-surface exchange with various terrestrial and aquatic compartments (Zhang et al., 2009; Wang et al., 2014, 2016). Previously deposited Hg can also be reduced to its elemental form and re-emitted back to the atmosphere (Gustin, 2012; Qureshi et al., 2012).

Atmospheric redox chemistry plays an important role in Hg long-range dispersion and deposition. However, the particular mechanisms of $\mathrm{Hg}$ oxidation in the atmosphere are not well understood (Lin et al., 2006; Subir et al., 2011, 2012; Gustin et al., 2015; Ariya et al., 2015). Gaseous reactive halogens, in particular atomic bromine $(\mathrm{Br})$, are believed to play a major role in atmospheric oxidation of GEM (Goodsite et al., 2004, 2012; Donohoue et al., 2006; Hynes et al., 2009). Observational evidence exists that Br-initiated chemistry is a dominant GEM oxidation pathway in some atmospheric environments, including the marine boundary layer, the polar regions, and the upper troposphere and lower stratosphere (Hedgecock and Pirrone, 2004; Holmes et al., 2009; Lyman and Jaffe, 2010; Obrist et al., 2011; Gratz et al., 2015). However, very limited data exist with respect to this mechanism in the global atmosphere (Kos et al., 2013). Nevertheless, use of the $\mathrm{Br}$ chemistry as the only oxidation pathway in a chemical transport model enables simulation of the $\mathrm{Hg}$ atmospheric cycle and reproduction of available observations (Holmes et al., 2010; Soerensen et al., 2010; Amos et al., 2012; Shah et al., 2016). However, in spite of theoretical doubts about the viability and significance of direct GEM oxidation by ozone $\left(\mathrm{O}_{3}\right)$ and hydroxyl radical $(\mathrm{OH})$ under atmospheric conditions (Calvert and Lindberg, 2005; Hynes et al., 2009), numerous modeling studies using these reactions as the main GEM oxidation pathways in the free troposphere also demonstrate reasonable results compared with observed GEM concentration and wet deposition flux (Christensen et al., 2004; Travnikov and Ilyin, 2009; Pan et al., 
2010; Baker et al., 2012; Kos et al., 2013; Gencarelli et al., 2014; De Simone et al., 2015; Cohen et al., 2016). Besides, both theoretical and laboratory studies suggest that complex $\mathrm{Hg}$ oxidation mechanisms involving $\mathrm{O}_{3}$ and $\mathrm{OH}$ can exist in the atmosphere in the presence of aerosol particles and secondary reactants (Snider et al., 2008; Cremer et al., 2008; Rutter et al., 2012; Subir et al., 2012; Ariya et al., 2015). Note that recent comparative studies have shown that models with diverse atmospheric chemistry formulations agree well when used to simulate $\mathrm{Hg}$ transport on a global scale and the source attribution of $\mathrm{Hg}$ deposition (Travnikov et al., 2010; AMAP/UNEP, 2013a, 2015).

Chemical transport models complemented by extensive measured data can facilitate a better understanding of the principal mechanisms governing $\mathrm{Hg}$ dispersion and cycling in the atmosphere. The effects of atmospheric redox chemistry as well as anthropogenic and natural emissions on the fate of atmospheric $\mathrm{Hg}$ were investigated systematically in a number of earlier modeling studies (Seigneur et al., 2006; Seigneur and Lohman, 2008; Lohman et al., 2008). In more recent work, Kos et al. (2013) performed a detailed analysis of the uncertainties associated with RM measurement and modeling. A number of model sensitivity runs were carried out to evaluate different chemical mechanisms and speciation of anthropogenic $\mathrm{Hg}$ emissions. In particular, they found evident inconsistencies between the emission speciation in existing emission inventories and the measured RM concentration in surface air. Weiss-Penzias et al. (2015) used a global-scale $\mathrm{Hg}$ model to analyze speciated atmospheric $\mathrm{Hg}$ measurements from five high- and mid-elevation sites. The results of the study suggested the presence of different chemical regimes in different parts of the troposphere and signalled that there is not necessarily one single global oxidant. Shah et al. (2016) used the same chemical transport model to interpret aircraft measurements of RM and to place new constraints on Br-initiated chemistry in the free troposphere. They found that standard model simulations significantly underestimated observed RM and that modeling with tripled $\mathrm{Br}$ concentrations or a faster oxidation rate constant improved agreement with observations. A detailed processspecific atmospheric lifetime analysis was carried out by Cohen et al. (2016) and provided important insights into the fate and transport of atmospheric $\mathrm{Hg}$ as well as total $\mathrm{Hg}$ deposition to the Great Lakes. A global-scale chemical transport model was also used by Song et al. (2015) for inverse modeling aimed at constraining present-day atmospheric $\mathrm{Hg}$ emissions and relevant physiochemical parameters.

The current study uses four contemporary global-scale $\mathrm{Hg}$ chemical transport models in combination with a variety of long-term $\mathrm{Hg}$ concentration and wet deposition measurements from different monitoring networks to analyze processes governing $\mathrm{Hg}$ fate in the atmosphere. A number of numerical experiments have tried to evaluate the effect of anthropogenic and natural/secondary emissions as well as different chemical oxidation mechanisms on the levels and spa- tiotemporal variation of GEM and RM air concentrations and $\mathrm{Hg}$ wet deposition. This study was performed as part of the Mercury Modelling Task Force, a scientific cooperative initiative under the EU-funded project, Global Mercury Observation System (GMOS, www.gmos.eu).

\section{Methods}

\subsection{Measurements}

A variety of measured data were used to evaluate the model experiments. The measured dataset was based on the global GMOS monitoring network for $\mathrm{Hg}$ (Sprovieri et al., 2016, 2017; GMOS, 2016), complemented by data from the European Monitoring and Evaluation Programme (EMEP) regional network for Europe (Tørseth et al., 2012; EMEP, 2016) and by data from the Mercury Deposition Network of the National Atmospheric Deposition Program (NADP/MDN) (Prestbo and Gay, 2009; NADP/MDN, 2016), the Atmospheric Mercury Network (AMNet) (Gay et al., 2013; AMNet, 2016), and the Canadian National Atmospheric Chemistry Database (NAtChem) (Cole et al., 2013; Steffen et al., 2015; NAtChem, 2016) for North America. Available measurements of GEM, GOM, and PBM concentrations in air were compiled, as well as wet deposition flux measurements performed at ground-based sites in 2013. At most of the sites of interest, the unspeciated measurements of atmospheric $\mathrm{Hg}$ were performed as GEM (Gay et al., 2013; Sprovieri et al., 2016; Angot et al., 2016). However, the scientific evidence is still incomplete as to whether GEM or total gaseous mercury (TGM) concentration is measured at some particular sites because this largely depends on local ambient conditions and the configuration of the measurement setup (Gustin et al., 2015; Slemr et al., 2015). Nevertheless, because the difference between long-term observations of GEM and TGM commonly does not exceed a few percentage points (Slemr et al., 2015), all unspeciated $\mathrm{Hg}$ measurements were interpreted as GEM. Measured values of RM are used in the study instead of observations of individual species GOM and PBM. RM appears to be more valuable for the analysis because measurements of the individual species are associated with higher uncertainties (Gustin et al., 2015; WeissPenzias et al., 2015). Therefore, only sites with co-located observations of GOM and PBM were used in the study.

The original measured data with high temporal resolution were processed to obtain monthly and yearly mean values. According to accepted criteria, monthly averages were used for the analysis when the original data covered at least 15 days of the month. Monthly averages were used both to generate yearly mean values and to characterize the seasonal variation of the observed parameter. In both cases, only sites with temporal coverage of at least 7 months were selected. The characteristics of the selected sites measuring GEM, $\mathrm{RM}$, and wet deposition are given, respectively, in Tables S1, 


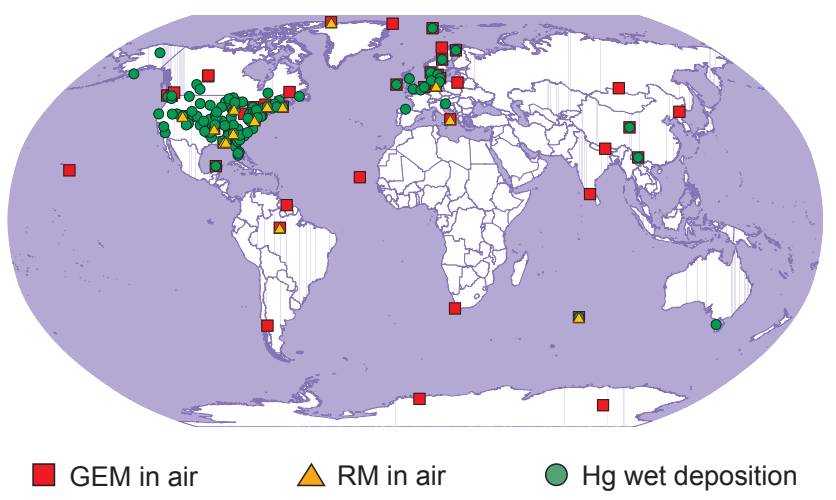

Figure 1. Location of measurement sites used in the study

S2, and S3 in the Supplement. The geographical location of the whole collection of sites is shown in Fig. 1. In total, the dataset included 49 sites measuring GEM, 14 sites measuring RM, and 124 sites measuring wet deposition. GEM observations are relatively uniformly distributed over the globe, with somewhat higher density in the Northern Hemisphere. In contrast, RM is observed mostly in northern temperate latitudes, with only a few sites located in the tropics and further southward. Most wet deposition measurements are located in North America and Europe, limiting the possibility of model evaluation in other regions.

\subsection{Models}

The model ensemble used in this study includes four chemical transport models simulating mercury on a global scale (Table 1). The models differ considerably in their general formulation, spatial resolution, and physical and chemical process parameterizations. The horizontal spatial resolution of the models ranges from 1 to $2.8^{\circ}$ in latitude and longitude. The upper boundaries of the model domains vary from $10 \mathrm{hPa}(\sim 30 \mathrm{~km})$ to $0.01 \mathrm{hPa}(\sim 80 \mathrm{~km})$. Hence, the models cover the entire troposphere and at least a significant part of the stratosphere, which is enough to take into account most processes governing mercury dispersion in the atmosphere. Two of the models (GLEMOS, and GEOS-Chem) use offline meteorological data prepared by an external pre-processor, whereas the other two (GEM-MACH-Hg and ECHMERIT) generate the meteorological fields along with the simulation of pollutant transport. All the models used the same $\mathrm{Hg}$ anthropogenic emissions dataset (AMAP/UNEP, 2013a, b), with somewhat different speciations of mercury forms in the base case. In the other model experiments, the emissions speciation was harmonized by assuming all emissions to be a form of GEM (Table 2). By contrast, total values of natural and secondary emissions differed significantly among the models. Parameterization of these processes is an essential element of the model setup describing $\mathrm{Hg}$ cycling between the Earth's surface and the atmosphere, which cannot be easily changed or removed without disturbing the entire model balance. The major chemical mechanisms in the standard model configuration in the base case were also essentially different. The base-case reactions of GLEMOS and ECHMERIT included $\mathrm{Hg}$ oxidation by $\mathrm{O}_{3}$ and $\mathrm{OH}$. The GEM-MACH-Hg chemical scheme was based on the reaction with $\mathrm{OH}$, with $\mathrm{Br}$ chemistry applied in the polar regions. GEOS-Chem considered $\mathrm{Br}$ chemistry as the only $\mathrm{Hg}$ oxidation pathway in the gas phase. In addition, two of the four models (GLEMOS and ECHMERIT) also included $\mathrm{Hg}$ redox chemistry in the aqueous phase in cloud water. However, it should be noted that the numerical experiments in this study (see Sect. 2.4) were formulated to investigate particular processes when all models used the same chemical mechanisms. Considering these differences, the results, whether the models succeed or fail in reproducing the observed dependencies, appear to be particularly valuable. A more detailed description of the model parameterizations is given subsequently.

\subsubsection{GLEMOS}

GLEMOS is a multi-scale chemical transport model developed to simulate environmental dispersion and cycling of various chemicals including $\mathrm{Hg}$ based on the older MSCEHM-Hem hemispheric model (Travnikov, 2005; Travnikov and Ilyin, 2009; Travnikov et al., 2009). The model simulates atmospheric transport, chemical transformation, and deposition of three $\mathrm{Hg}$ species (GEM, GOM, and PBM). Atmospheric transport of the tracers is driven by meteorological fields generated by the Weather Research and Forecast modeling system (WRF) (Skamarock et al., 2007) fed by operational analysis data from the European Centre for MediumRange Weather Forecasts (ECMWF) (ECMWF, 2017). In the base configuration, the model grid had a horizontal resolution of $1^{\circ} \times 1^{\circ}$. Vertically, the model domain reached $10 \mathrm{hPa}$ and consisted of 20 irregular terrain-following sigma layers. The atmospheric chemical scheme included $\mathrm{Hg}$ oxidation and reduction chemical reactions in both the gaseous phase and aqueous phase of cloud water. The major chemical mechanisms in the gas phase included $\mathrm{Hg}$ oxidation by $\mathrm{O}_{3}$ and $\mathrm{OH}$ radical, with the reaction rate constants from Hall (1995) and Sommar et al. (2001), respectively. The latter mechanism was scaled down by a factor of 0.1 in the cloud environment and below clouds to account for reduced photochemical activity (Seigneur et al., 2001). The $\mathrm{O}_{3}$ and $\mathrm{OH}$ concentration fields were imported from MOZART (Emmons et al., 2010). Two-step gas-phase oxidation of GEM by $\mathrm{Br}$ was included as an option. Aqueous-phase reactions include oxidation by $\mathrm{O}_{3}, \mathrm{OH}$, and $\mathrm{Cl}$ and reduction by decomposition of sulfite complexes (Van Loon et al., 2000). The model distinguished between in-cloud and sub-cloud wet deposition of PBM and GOM based on empirical data. The dry deposition scheme was based on the resistance analogy approach (Wesely and Hicks, 2000). Prescribed fluxes of $\mathrm{Hg}$ natural and secondary emissions from soil and seawater were generated depending on $\mathrm{Hg}$ soil concentration, soil temperature, and solar radia- 
Table 1. Characteristics of the participating global chemistry transport models.

\begin{tabular}{|c|c|c|c|c|}
\hline Model & GLEMOS & GEOS-Chem & GEM-MACH-Hg & ECHMERIT \\
\hline \multicolumn{5}{|l|}{ Spatial resolution } \\
\hline Horizontal & $1^{\circ} \times 1^{\circ}$ & $2.5^{\circ} \times 2^{\circ}$ & $1^{\circ} \times 1^{\circ}$ & $\mathrm{T} 42\left(\sim 2.8^{\circ} \times 2.8^{\circ}\right)$ \\
\hline Vertical & 20 levels, top $10 \mathrm{hPa}$ & 47 levels, top $0.01 \mathrm{hPa}$ & 58 levels, top $7 \mathrm{hPa}$ & $\begin{array}{l}19 \text { levels, top } \\
10 \mathrm{hPa}\end{array}$ \\
\hline \multicolumn{5}{|l|}{ Driving meteorology } \\
\hline Data support type & off-line & off-line & on-line & on-line \\
\hline Meteorological driver & WRF/ECMWF & GEOS-FP & GEM & ECHAM5 \\
\hline \multicolumn{5}{|l|}{ Anthropogenic emission } \\
\hline Global emission, $\mathrm{t} / \mathrm{y}$ & 1875 & 1875 & 1875 & 1875 \\
\hline Average speciation (base case) & & & & \\
\hline GEM : GOM : PBM & $81: 15: 4$ & $81: 19: 0^{\mathrm{a}}$ & $96: 3: 1$ & $81: 15: 4$ \\
\hline \multicolumn{5}{|l|}{ Natural and re-emission } \\
\hline Definition & prescribed/dynamic $^{\mathrm{b}}$ & prescribed/dynamic $^{c}$ & prescribed/dynamic $^{\mathrm{d}}$ & prescribed/dynamic ${ }^{\mathrm{e}}$ \\
\hline Global emission, $\mathrm{t} / \mathrm{y}$ (base case) & 3995 & 5070 & 3660 & 8600 \\
\hline \multicolumn{5}{|c|}{ Gaseous chemistry (base-case reactions are in bold) } \\
\hline \multicolumn{5}{|c|}{ Reaction rates ${ }^{\mathrm{f}}, \mathrm{cm}^{3} \mathrm{molec}^{-1} \mathrm{~s}^{-1}$} \\
\hline $\mathrm{Hg}^{0}+\mathrm{Br} \rightarrow \mathrm{HgBr}$ & $3.7 \times 10^{-13 \mathrm{~g}}$ & $3.7 \times 10^{-13} \mathrm{~g}$ & $3.7 \times 10^{-13 \mathrm{~g}}$ & $3.7 \times 10^{-13 \mathrm{~g}}$ \\
\hline $\mathrm{HgBr} \rightarrow \mathrm{Hg}^{0}+\mathrm{Br}$ & $9.4 \times 10^{-2} \mathrm{~s}^{-1 \mathrm{~h}}$ & $9.4 \times 10^{-2} \mathrm{~s}^{-1 h}$ & $1.7 \times 10^{-1} \mathrm{~s}^{-1 \mathrm{i}}$ & $9.4 \times 10^{-2} \mathrm{~s}^{-1 \mathrm{~h}}$ \\
\hline $\mathrm{HgBr}+\mathrm{Br} \rightarrow \mathrm{Hg}^{0}+\mathrm{Br}_{2}$ & $3.9 \times 10^{-11 \mathrm{j}}$ & $3.9 \times 10^{-11} \mathrm{j}$ & - & - \\
\hline $\begin{array}{l}\mathrm{HgBr}+\mathrm{Y} \rightarrow \mathrm{HgBrY} \\
\mathrm{Y}=\mathrm{Br}, \mathrm{OH}\end{array}$ & $2.5 \times 10^{-10 \mathrm{k}}$ & $2.5 \times 10^{-10 k}$ & $2.5 \times 10^{-10 \mathrm{k}}$ & $2.5 \times 10^{-10 \mathrm{k}}$ \\
\hline $\mathrm{Hg}^{0}+\mathrm{O}_{3} \rightarrow \mathrm{Hg}(\mathrm{II})$ & $3.0 \times 10^{-201}$ & - & $3.0 \times 10^{-201}$ & $3.0 \times 10^{-201}$ \\
\hline $\mathrm{Hg}^{0}+\mathrm{OH} \rightarrow \mathrm{Hg}(\mathrm{II})$ & $(0.9-8.7) \times 10^{-14} \mathrm{~m}$ & - & $3.0 \times 10^{-14 n}$ & $8.7 \times 10^{-14}$ o \\
\hline \multicolumn{5}{|l|}{ Aqueous chemistry (in cloud water) } \\
\hline Oxidation agents & $\mathrm{O}_{3}, \mathrm{OH}, \mathrm{HOCl} / \mathrm{OCl}^{-}$ & - & - & $\mathrm{O}_{3}, \mathrm{OH}$ \\
\hline Reduction agents & $\mathrm{SO}_{3}^{=}$ & - & - & - \\
\hline Model & GLEMOS & GEOS-Chem & GEM-MACH-Hg & ECHMERIT \\
\hline Reference & $\begin{array}{l}\text { Travnikov and Ilyin } \\
(2009) \text {, Travnikov et } \\
\text { al. (2009) }\end{array}$ & $\begin{array}{l}\text { Holmes et al. (2010), } \\
\text { Amos et al. (2012), } \\
\text { Song et al. (2015) }\end{array}$ & $\begin{array}{l}\text { Durnford et al. (2012), } \\
\text { Kos et al. (2013), Das- } \\
\text { toor et al. (2015) }\end{array}$ & $\begin{array}{l}\text { Jung et al. (2009), } \\
\text { De Simone et al. } \\
\text { (2014) }\end{array}$ \\
\hline
\end{tabular}

${ }^{a}$ Dynamic gas-particle partitioning of RM in the atmosphere according to Amos et al. (2012). ${ }^{\text {b }}$ Prescribed fluxes from terrestrial and aquatic surfaces as a function of temperature and solar radiation; dynamic re-emission from snow. ${ }^{c}$ Prescribed fluxes from terrestrial surfaces as a function of temperature and solar radiation; dynamic fluxes from aquatic surfaces based on multi-media modeling. ${ }^{\mathrm{d}}$ Prescribed fluxes from terrestrial surfaces as a function of solar radiation and leaf area index; dynamic re-emission from snow and aquatic surfaces. ${ }^{\mathrm{e}}$ Prescribed fluxes from terrestrial surfaces as a function of temperature and solar radiation; dynamically calculated ocean emissions. ${ }^{\mathrm{f}}$ Temperature and pressure dependence applied to most reactions; the reaction rates are given at $298 \mathrm{~K}$ and 1 atm. ${ }^{\mathrm{g}}$ Donohoue et al. (2006). ${ }^{\mathrm{h}}$ Goodsite et al. (2012). ${ }^{\mathrm{i}}$ Dibble et al. (2012). ${ }^{\mathrm{j}}$ Balabanov et al. (2005). ${ }^{\mathrm{k}}$ Goodsite et al. (2004). ${ }^{\mathrm{l}}$ Hall (1995). ${ }^{\mathrm{m}}$ Sommar et al. (2001) scaled down by a factor 0.1 in the cloud environment and below clouds to account for reduction of photochemical activity (Seigneur et al., 2001). ${ }^{\mathrm{n}}$ Sommar et al. (2001) scaled down by a factor 0.34 to take into account possible dissociation/reduction reactions. ${ }^{\circ}$ Sommar et al. (2001). ${ }^{\mathrm{P}}$ Parrella et al. (2012). ${ }^{\mathrm{q}}$ Yang et al. (2005, 2010). ${ }^{\mathrm{r}}$ Emmons et al. (2010).

tion for emissions from land and proportionally to primary production of organic carbon in seawater for emissions from the ocean (Travnikov and Ilyin, 2009). In addition, an empirical parameterization of prompt $\mathrm{Hg}$ re-emission from snowand ice-covered surfaces based on observed data was used.

\subsubsection{GEOS-Chem}

The GEOS-Chem global chemical transport model (v902; www.geos-chem.org) is driven by assimilated meteorological data from the NASA GMAO Goddard Earth Observing System (Bey et al., 2001). GEOS-FP and GEOS-
5.2.0 data were used for the 2013 simulation year and the spinup period, respectively (http:/gmao.gsfc.nasa.gov/ products/). GEOS-Chem couples a 3-D atmosphere (Holmes et al., 2010), a 2-D mixed-layer slab ocean (Soerensen et al., 2010), and a 2-D terrestrial reservoir (Selin et al., 2008) at a horizontal resolution of $2^{\circ} \times 2.5^{\circ}$. Three $\mathrm{Hg}$ tracers (GEM, GOM, and PBM) were tracked in the atmosphere (Amos et al., 2012). A two-step gaseous oxidation mechanism initialized by $\mathrm{Br}$ atoms was used. Br fields were archived from a full-chemistry GEOS-Chem simulation (Parrella et al., 2012), and the reaction rate constants were obtained from 
Table 2. Specifications of model experiments.

\begin{tabular}{llll}
\hline Code & Anthropogenic emissions & Gas-phase chemistry & Comment \\
\hline BASE & UNEP2010 $^{\text {a }}$ & Model standard configuration & Base run \\
NoANT & No emission & Model standard configuration & Effect of anthropogenic emissions \\
NoNAT $^{b}$ & - & - & Effect of natural/secondary emissions \\
BrCHEM1 & UNEP2010, all emissions as GEM & GEM oxidation by Br & Br dataset from GEOS-Chem \\
BrCHEM2 & UNEP2010, all emissions as GEM & GEM oxidation by Br & Br dataset from p-TOMCAT $^{\mathrm{e}}$ \\
O3CHEM & UNEP2010, all emissions as GEM & GEM oxidation by $\mathrm{O}_{3}$ & O $_{3}$ dataset from MOZART $^{\mathrm{f}}$ \\
OHCHEM & UNEP2010, all emissions as GEM & GEM oxidation by OH & ${\text { OH dataset from } \text { MOZART }^{\mathrm{f}}}$
\end{tabular}

${ }^{\mathrm{a}}$ AMAP/UNEP (2013b). ${ }^{\mathrm{b}}$ Virtual experiment obtained by subtraction of NoANT results from the BASE case. ${ }^{\mathrm{c}}$ All GOM and PBM emissions summed to GEM to keep constant total Hg emissions. ${ }^{d}$ Parrella et al. (2012). ${ }^{\text {e }}$ Yang et al. (2005, 2010). ${ }^{\text {f }}$ Emmons et al. (2010).

Goodsite et al. (2012), Donohoue et al. (2006), and Balabanov et al. (2005). The GEM surface fluxes included anthropogenic sources, biomass burning, and geogenic activities as well as bidirectional fluxes in atmosphere-terrestrial and atmosphere-ocean exchanges (Song et al., 2015). Biomass burning emissions were estimated using a global $\mathrm{CO}$ emissions database and an $\mathrm{Hg} / \mathrm{CO}$ volume ratio of $1 \times 10^{-7}$. Geogenic activities were spatially distributed based on the locations of $\mathrm{Hg}$ mines. For atmosphere-terrestrial exchange, GEOS-Chem treated evasion and dry deposition of GEM separately (Selin et al., 2008). Dry deposition was parameterized by a resistance-in-series scheme (Wesely, 1989). In addition, effective GOM uptake by sea-salt aerosols was also included over the ocean (Holmes et al., 2010). GEM evasion included volatilization from soil and rapid recycling of newly deposited $\mathrm{Hg}$. The former was estimated as a function of soil $\mathrm{Hg}$ content and solar radiation. The latter was modeled by recycling a fraction of wet/dry deposited RM to the atmosphere as GEM immediately after deposition (60\% for snowcovered land and $20 \%$ for all other land surfaces) (Selin et al., 2008). GEOS-Chem estimated atmosphere-ocean GEM exchange using a standard two-layer diffusion model. Ocean $\mathrm{Hg}$ in the mixed layer was assumed to interact not only with the atmospheric boundary layer but also with subsurface waters through entrainment and detrainment of the mixed layer and wind-driven Ekman pumping (Soerensen et al., 2010).

\subsubsection{GEM-MACH-Hg}

GEM-MACH-Hg is a new chemical transport model for $\mathrm{Hg}$ based on the GRAHM model developed by Environment and Climate Change Canada (Dastoor and Larocque, 2004; Dastoor et al., 2008; Durnford et al., 2010, 2012; Kos et al., 2013; Dastoor et al., 2015). GEM-MACH-Hg uses a newer version of the operational meteorological model of the Environment and Climate Change Canada. The horizontal resolution of the model is $1^{\circ} \times 1^{\circ}$. GEM is oxidized in the atmosphere by the $\mathrm{OH}$ radical. The reaction rate constant was obtained from Sommar et al. (2001) but was scaled down by a coefficient of 0.34 to account for possible dissociation and reduction reactions (Tossell et al., 2003; Goodsite et al., 2004). Gaseous oxidation of $\mathrm{Hg}$ by $\mathrm{Br}$ was modeled in the polar regions using reaction rate constants from Donohoue et al. (2006), Dibble et al. (2012), and Goodsite et al. (2004). Atmospheric mercury depletion events (AMDE) parameterization was based on $\mathrm{Br}$ production and chemistry and snow re-emission of GEM (Dastoor et al., 2008). OH fields were obtained from MOZART (Emmons et al., 2010), and $\mathrm{BrO}$ was derived from 2007-2009 satellite observations of $\mathrm{BrO}$ vertical columns. The associated $\mathrm{Br}$ concentration was then calculated from a photochemical steady state (Platt and Janssen, 1995). Dry deposition in GEM-MACH-Hg was based on the resistance approach (Zhang, 2001; Zhang et al., 2003). In the wet deposition scheme, GEM and GOM were partitioned between cloud droplets and air using a temperature-dependent Henry's law constant. Total global emissions from natural sources and reemissions of previously deposited $\mathrm{Hg}$ (from land and oceans) in GEM-MACH-Hg were based on global $\mathrm{Hg}$ budgets from Gbor et al. (2007), Shetty et al. (2008), and Mason (2009). Land-based natural emissions were spatially distributed according to the natural enrichment of $\mathrm{Hg}$. Land re-emissions were spatially distributed according to historic $\mathrm{Hg}$ deposition and land-use type and were dependent on solar radiation and the leaf area index. Oceanic emissions depended on the distributions of primary production and atmospheric deposition.

\subsubsection{ECHMERIT}

ECHMERIT is a global online chemical transport model derived from the ECHAM5 global circulation model, with a highly flexible chemistry mechanism designed to facilitate the investigation of atmospheric $\mathrm{Hg}$ chemistry (Jung et al., 2009; De Simone et al., 2014, 2015, 2017). The model uses the same spectral grid as ECHAM. The standard horizontal resolution of the model is T42 (approximately $2.8^{\circ} \times 2.8^{\circ}$ ), whereas in the vertical dimension the model is discretized with a hybrid-sigma pressure system with non-equidistant levels up to $10 \mathrm{hPa}$. The base chemical mechanism includes GEM oxidation by $\mathrm{OH}$ and $\mathrm{O}_{3}$ in the gaseous and aqueous phases. Reaction rate constants were obtained from Sommar et al. (2001), Hall (1995), and Munthe (1992). OH and $\mathrm{O}_{3}$ concentration fields were imported from MOZART 
(Emmons et al., 2010). Hg oxidation by $\mathrm{Br}$ was also optionally available by means of a two-step gas-phase oxidation mechanism with reaction rates from Goodsite et al. (2004), Goodsite et al. (2012), and Donohoue et al. (2006). ECHMERIT parameterized dynamic air-seawater exchange as a function of ambient parameters, but using a constant value of $\mathrm{Hg}$ concentration in seawater (De Simone et al., 2014). Emissions from soils and vegetation were calculated offline and derived from the EDGAR/POET emission inventory (Granier et al., 2005; Peters and Olivier, 2003), which included biogenic emissions from the GEIA inventories (http://www.geiacenter.org), as described in Jung et al. (2009). Prompt re-emission of a fixed fraction (20\%) of wet and dry deposited $\mathrm{Hg}$ was included to account for reduction and evasion processes that govern short-term $\mathrm{Hg}$ cycling between the atmosphere and terrestrial reservoirs (Selin et al., 2008). This fraction was increased to $60 \%$ for snow-covered land and ice-covered seas.

\subsection{Emissions data}

A global inventory of $\mathrm{Hg}$ anthropogenic emissions for 2010 (AMAP/UNEP, 2013a, b) was used in the study. The original dataset consisted of gridded emission data with a spatial resolution of $0.5^{\circ} \times 0.5^{\circ}$ for three $\mathrm{Hg}$ species (GEM, GOM, and PBM). Total global Hg emissions from anthropogenic sources were estimated at 1875 tonnes per year, with the overall shares of GEM, GOM, and PBM emissions equal to 81,15 , and $4 \%$, respectively. As mentioned earlier, some models modified the original speciation of anthropogenic emissions (Table 1) in the BASE case simulation. No information on temporal variability of emissions was available in the dataset. Geographically, significant $\mathrm{Hg}$ emissions were predicted in industrial regions of East and South Asia, central Europe, and the eastern part of North America (Fig. S1 in the Supplement). In addition, high emission fluxes characterized some areas of Central and South America, sub-Saharan Africa, and Southeast Asia due to $\mathrm{Hg}$ releases from artisanal and small-scale gold mining. Almost no emissions were predicted in the Arctic and Antarctic regions.

\subsection{Model experiments}

The study was organized as multiple model experiments to evaluate particular processes and mechanisms of $\mathrm{Hg}$ atmospheric chemistry as well as anthropogenic and natu$\mathrm{ral} / \mathrm{secondary}$ emissions. A summary of the model experiments is given in Table 2. All the models were used to perform the BASE case simulation representing the state-ofthe-art model configuration, which was used as a reference point for other model experiments. All the models used the same anthropogenic emissions, but with model specific speciation (Sect. 2.3). The NoANT run was based on the same standard model configuration, but with anthropogenic emissions turned off. Because $\mathrm{Hg}$ emissions from natural and secondary sources were fully or partly represented in the models as bi-directional air-surface exchange fluxes or as re-emissions of previously deposited $\mathrm{Hg}$ (Table 1), simple exclusion of this emission type from the simulations was not feasible without disturbing the whole $\mathrm{Hg}$ cycle in the model. In contrast, assuming additivity of $\mathrm{Hg}$ processes in the atmosphere with respect to contributions from different sources, the effect of natural and secondary emissions (NoNAT) could be estimated by subtracting the NoANT results from the BASE case. Four additional model experiments were intended to evaluate different chemical mechanisms of GEM oxidation in the atmosphere. To avoid the influence of direct anthropogenic emissions on simulated RM concentrations, all emissions were assumed to be a form of GEM. The BrCHEM1 and BrCHEM2 model runs included a single mechanism of GEM oxidation by atomic $\mathrm{Br}$, but using two different datasets of $\mathrm{Br}$ concentration in the atmosphere: one simulated by GEOS-Chem (Parrella et al., 2012) and the other by p-TOMCAT (Yang et al., 2005, 2010). A comparison of the spatial and temporal variations in $\mathrm{Br}$ concentration from these two datasets is given in Figs. S7 and S10 in the Supplement. Two other experiments, O3CHEM and $\mathrm{OHCHEM}$, were based on $\mathrm{O}_{3}$ - and $\mathrm{OH}$-initiated oxidation chemistry. The models used the same $\mathrm{O}_{3}$ and $\mathrm{OH}$ concentration datasets extracted from MOZART model simulations results (Emmons et al., 2010). The spatial gradients and seasonal variation of the reactants are shown, respectively, in Figs. S8-S9 and S11-S12 in the Supplement. Note that not all models were used to perform the whole simulation program. The results presented below are based on available simulations for each particular experiment.

\subsection{Statistical analysis}

Modelling results were compared with observations using the following statistical parameters. Both spatial and temporal correlations of simulated and observed values were characterized by the Pearson correlation coefficient:

$R_{\mathrm{corr}}=\frac{\sum_{i}\left(M_{i}-\bar{M}\right)\left(O_{i}-\bar{O}\right)}{\sqrt{\sum_{i}\left(M_{i}-\bar{M}\right)^{2} \sum_{i}\left(O_{i}-\bar{O}\right)^{2}}}$,

where $M_{i}$ and $O_{i}$ are monthly or annual mean simulated and observed values, respectively, and $\bar{M}$ and $\bar{O}$ are average values. The averaging and summing were performed over monthly values to calculate temporal correlations at particular sites or over annual mean values for all sites to calculate spatial correlation coefficients. An arithmetic mean of all temporal correlation coefficients for individual sites was then used in the analysis. The discrepancy between simulated and observed values was characterized by a symmetric relative bias:

RBIAS $=2 \frac{\bar{M}-\bar{O}}{\bar{M}+\bar{O}} 100 \%$, 
where RBIAS varies within $\pm 200 \%$ and small deviations between model results and observations are characterized by values close to zero.

\section{Results and discussion}

\subsection{Gaseous elemental mercury}

The GEM concentration in air is a parameter representing the balance between $\mathrm{Hg}$ global emissions and sinks by chemical transformation to other $\mathrm{Hg}$ forms or direct interaction with the surface. Given the long residence time of GEM in the atmosphere, its spatiotemporal gradients likely characterize the distribution of global emission regions as well as long-range atmospheric dispersion and cycling in the atmosphere (Selin, 2009; Travnikov, 2012; Ariya et al., 2015). Figure 2 shows the global distribution of GEM concentration in surface air as simulated by four global models according to the BASE case, along with ground-based observations represented by colored circles in the same color palette. The models predicted spatial $\mathrm{Hg}$ concentration patterns with a pronounced gradient between the Southern Hemisphere (ca. 0.9-1.1 $\mathrm{ng} \mathrm{m}^{-3}$ ) and the Northern Hemisphere (ca. 1.1-1.6 $\mathrm{ng} \mathrm{m}^{-3}$ ) and elevated concentrations in the major industrial regions in East and South Asia, Europe, and North America (above $1.4 \mathrm{ng} \mathrm{m}^{-3}$ ). Elevated concentrations were also predicted in tropical areas of South America, central Africa, and Southeast Asia, where considerable $\mathrm{Hg}$ emissions from artisanal and smallscale gold mining are expected (AMAP/UNEP, 2013a). The models generally agreed with ground-based observations, as shown in Fig. 2. The measurements also provided evidence of a statistically significant interhemispheric gradient and relatively high concentrations in industrial regions (Sprovieri et al., 2016). A more detailed comparison of modeling results with measurements is given in Fig. S2 in the Supplement. The model-measurement divergence commonly did not exceed $\pm 30 \%$. In general, the models exhibited lower spatial variations in annual GEM concentration than did the measurements. This observation relates mostly to sites that are compactly located in North America and Europe. It can be explained by the relatively low spatial resolution of the model grids (1-2 hundreds of kilometers), which made it difficult for the models to reproduce the influence of local emission sources and specific meteorological conditions at measurement sites. Another reason can be associated with possible overestimation of GEM residence time in the atmosphere, leading to additional smoothing of the simulated concentration patterns. The possibility of a shorter GEM lifetime with respect to oxidation was recently proposed in Horowitz et al. (2017), but this would require the existence of a fast atmospheric reduction process to match observations.

The model-to-model difference in simulated GEM concentrations did not exceed $\pm 20 \%$ (see also Fig. S5 in the Supplement). Nevertheless, pronounced distinctions could be observed among the spatial patterns simulated by different models because of deviations in physical and chemical process parameterizations. As mentioned in Sect. 2.2, the various models used quite different chemical mechanisms of GEM oxidation in the atmosphere in their base configurations. Moreover, even if they used the same anthropogenic emissions data, they differed in their estimates of natural and secondary emissions and $\mathrm{Hg}$ air-surface exchange. As shown in Fig. 2 and Fig. S5 in the Supplement, all four models were in relatively agreement when simulating GEM concentrations in regions affected by direct anthropogenic emissions (e.g., eastern North America, western and central Europe, East Asia). However, the differences between the models became larger as the distance from emission regions increased. For instance, GLEMOS and ECHMERIT predicted lower GEM concentrations (below $1.3 \mathrm{ng} \mathrm{m}^{-3}$ ) over North America (mostly Canada) and eastern Siberia (Fig. 2a and d). This phenomenon was caused by two factors: use of $\mathrm{O}_{3}$ oxidation chemistry with elevated $\mathrm{O}_{3}$ concentrations in the northern midlatitudes (Fig. S8 in the Supplement) and use of relatively low levels of natural/secondary emissions over these regions. In particular, this led to some underestimation of observed GEM levels at North American sites. In contrast, GEM-MACH-Hg simulated higher GEM concentrations (above $1.4 \mathrm{ng} \mathrm{m}^{-3}$ ) than other models over the North Atlantic and Pacific oceans due to relatively high $\mathrm{Hg}$ evasion from seawater in these aquatic regions and use of the $\mathrm{OH}$ oxidation mechanism. The latter provided weak oxidative capacity in the temperate and high latitudes of both hemispheres due to the pronounced meridional profile of $\mathrm{OH}$ concentrations, with high values in the tropics (Fig. S9 in the Supplement). The elevated GEM concentrations over the Pacific generally agreed with observations at Mauna Loa site in Hawaii and at coastal sites in Europe (Fig. 2c). However, the former is a high-elevation site (3384 m a.s.1.), where conditions are more like those in the free troposphere. Besides, it can be affected by $\mathrm{Hg}$ emissions from the active $\mathrm{Ki}$ lauea volcano (Gay et al., 2013). Note that GLEMOS and ECHMERIT also used the $\mathrm{OH}$ mechanism in their base configurations. However, the effect described above diminished when used in combination with $\mathrm{O}_{3}$ chemistry. Simultaneous use of these two oxidation mechanisms can probably lead to surplus GEM oxidation or imply the existence of an $\mathrm{Hg}$ reduction mechanism in the atmosphere. In particular, it can explain some underestimation of observed GEM concentrations over the oceans by ECHMERIT. The effect was less pronounced in the case of GLEMOS because it used a reduced rate constant for the reaction with $\mathrm{OH}$ (Table 1). Use of $\mathrm{Br}$ chemistry by GEOS-Chem provided reasonable agreement with most observations (Fig. 2b). Unlike GEM-MACH-Hg, it simulated lower GEM concentrations over the North Atlantic and Pacific oceans, somewhat underestimating available observations in these regions. Note that the Br oxidation mechanism predicted strong GEM oxidation in the southern high latitudes due to high $\mathrm{Br}$ concentrations 

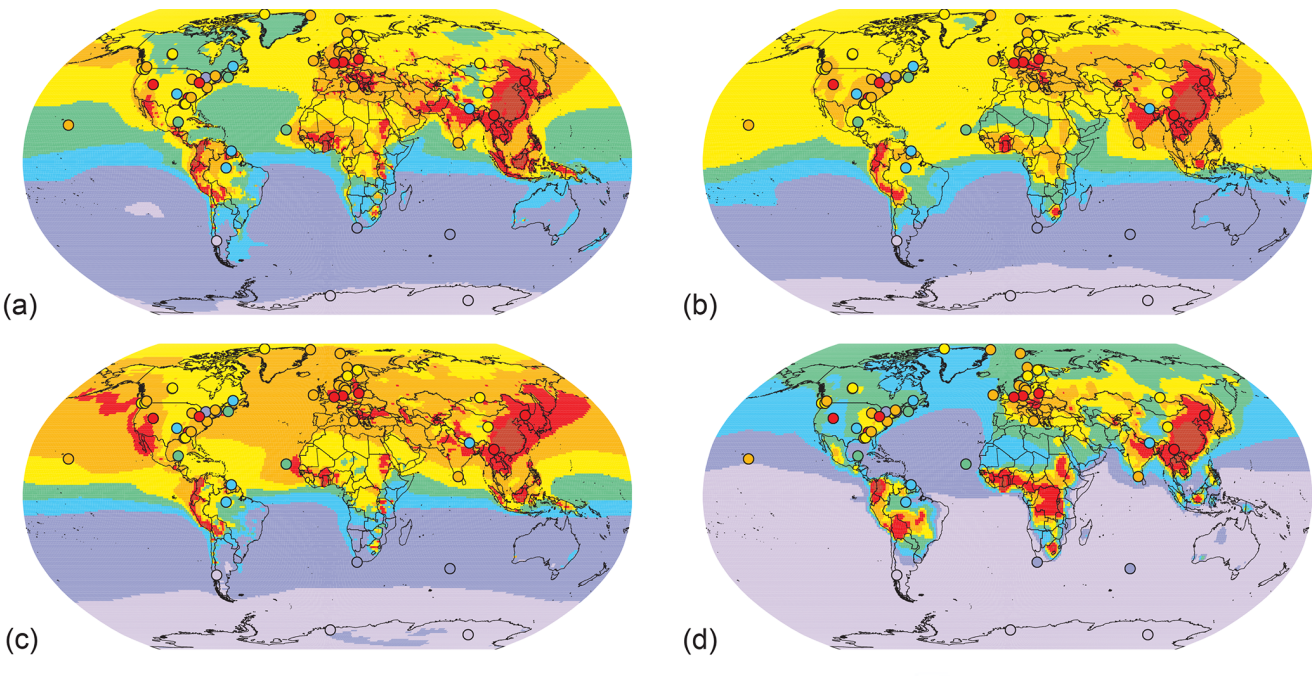

$\begin{array}{llllllll}0 & 1 & 1.1 & 1.2 & 1.3 & 1.4 & 1.6 & 2.4 \mathrm{ng} \mathrm{m}^{-3}\end{array}$

Figure 2. Spatial distribution of GEM air concentration in 2013 simulated according to the BASE case by four global models: (a) GLEMOS, (b) GEOS-Chem, (c) GEM-MACH-Hg, and (d) ECHMERIT. Circles show observed values in the same color scale.

(Fig. S7 in the Supplement), which was compensated for by large re-emission fluxes from seawater, leading to intensive air-surface exchange in this region. All models tended to overpredict GEM concentrations in the northern part of South America as measured at two sites: Manaus (Brazil) and Nieuw Nickerie (Surinam). As mentioned earlier, the high simulated concentrations in this region were caused by large expected emissions from artisanal and small-scale gold mining, which were probably overestimated.

Figure 3 illustrates an analysis of the interhemispheric GEM concentration gradient. The figure shows the meridional distribution of both observed and model-predicted concentrations in surface air. The latter are split into two fractions contributed by anthropogenic and natu$\mathrm{ral} / \mathrm{secondary}$ sources. All four models reproduced the observed GEM concentration differences between the Southern and Northern hemispheres. The lowest concentrations (below $1 \mathrm{ng} \mathrm{m}^{-3}$ )were typical of the high and temperate latitudes of the Southern Hemisphere. There was a weak maximum of zonal-mean GEM concentration $\left(1.4-1.6 \mathrm{ng} \mathrm{m}^{-3}\right)$ in the temperate latitudes of the Northern Hemisphere, corresponding to the location of most anthropogenic emission sources. Hence, the interhemispheric gradient is largely formed by the contribution of direct anthropogenic emissions, which is larger in the Northern Hemisphere. The contribution of natural and secondary emissions also increases northward, but the gradient is commonly smaller. The models predicted some decrease in concentrations further northward, which was not evident from the observations. This decrease was mostly connected with underestimation of $\mathrm{Hg}$ re-emissions from snow and seawater. More detailed analysis of the modeling results in the polar regions and a comparison with measurements performed in the Arctic and Antarctica is given in the companion paper (Angot et al., 2016). In particular, three of the four models successfully reproduced the springtime GEM concentration minimum caused by occurrence of AMDEs. However, the models tended to underestimate the summertime maximum, which is determined by revolatilization from snowpack and meltwater and evasion from the ocean.

Statistics for simulated and observed GEM concentrations for different model experiments (Table 2) are illustrated in Fig. 4 in terms of spatial and temporal correlation coefficients and relative bias. Details of the statistics used are given in Sect. 2.5. In the BASE simulation, all models produced concentration distributions that agreed well with measurements (the spatial correlation coefficient was about 0.7 and the bias approximately zero). However, the models differed in their ability to reproduce temporal GEM variations in surface air. The temporal correlation coefficient between simulated and observed monthly mean values varied between -0.3 and 0.5 . (Fig. 4c). Sprovieri et al. (2016) found a consistent seasonal cycle of observed GEM concentration at most measurement sites in both Northern and Southern hemispheres, with higher concentrations during winter and spring and lower concentrations in summer and fall. However, it should be noted that the seasonal variation of monthly mean concentration was not significant at temperate and low latitudes, where most of the sites were located, and commonly did not exceed $\pm 20 \%$. Therefore, reproduction of GEM temporal variation is a challenging task for models in the absence of data on seasonal variation in the anthropogenic emissions used in this study (AMAP/UNEP, 2013b).

Switching off anthropogenic emissions (NoANT) led to a decrease in GEM levels in the atmosphere (the bias was 

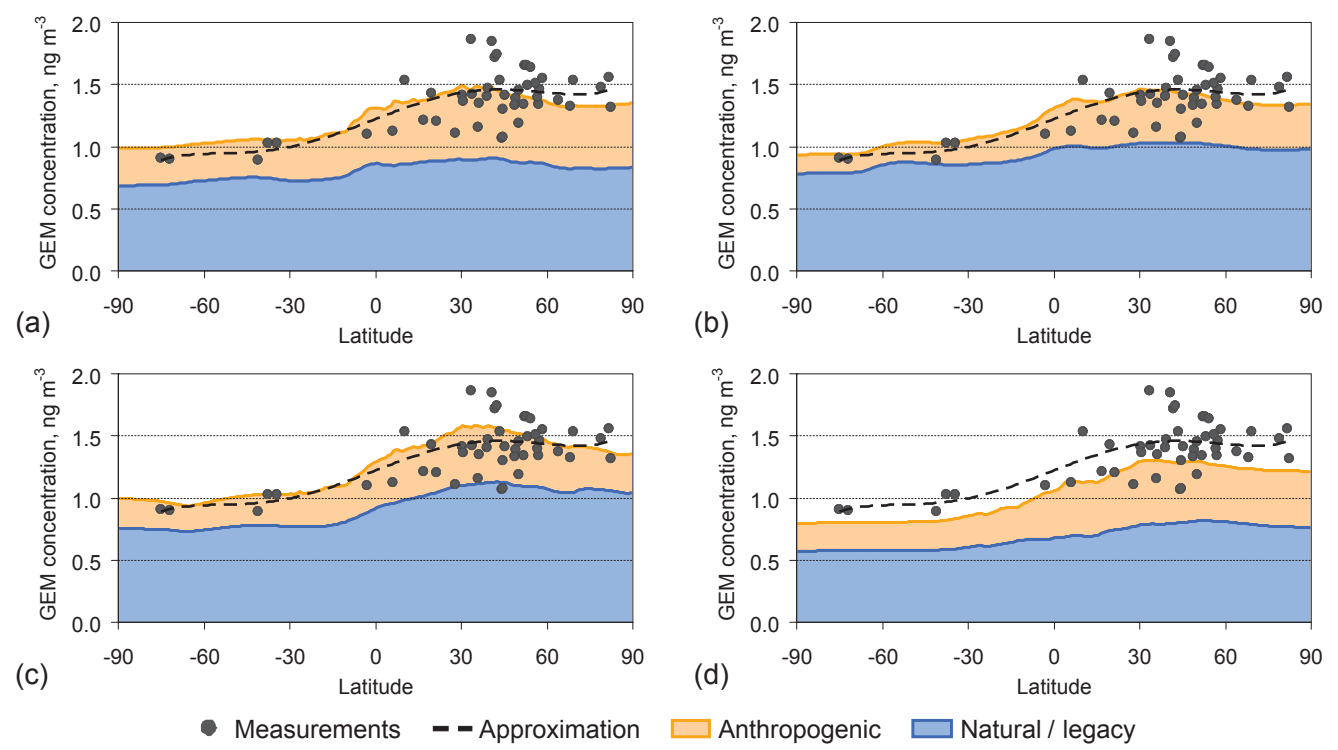

Figure 3. Global zonal-mean distribution of GEM air concentration in 2013 simulated by four models: (a) GLEMOS, (b) GEOS-Chem, (c) GEM-MACH-Hg, and (d) ECHMERIT. Black dots are the same observations as in Fig. 2 and the dotted line is a polynomial approximation.

$-40 \%)$ and some decrease in the spatial correlation with measurements. It is worth noting that the spatial distribution of $\mathrm{Hg}$ concentrations in this experiment was largely determined by model-specific natural and secondary emissions and that therefore the change in spatial correlation differed considerably among the models. Removing anthropogenic emissions from the model simulations did not affect the temporal variation of the modeling results. In contrast, the results of the experiment with no natural and secondary emissions (NoNAT) demonstrated significant improvement in temporal correlation with measurements for the models that showed poor correlations in the base run. Besides, the exclusion of natural and secondary emissions led to some decrease in spatial correlation and a large negative bias $(\simeq 100 \%)$. Simulations with different chemical mechanisms (BrCHEM1, BrCHEM2, O3CHEM, and OHCHEM) provided somewhat different spatial GEM concentration patterns in surface air. The model run with the first $\mathrm{Br}$ dataset (BrCHEM1) showed practically unbiased results, whereas the GEM concentrations from the BrCHEM2 run based on the second dataset were biased high (Fig. 4b) due to the lower $\mathrm{Br}$ concentrations provided by this dataset compared to the first one (Fig. S7 in the Supplement). The O3CHEM and OHCHEM simulations also showed a positive bias, indicating the smaller oxidation capacities of these mechanisms. The spatial correlation coefficient varied among the model runs with different chemical mechanisms (0.61-0.73). Somewhat higher spatial correlations were obtained for the oxidation reactions with $\mathrm{Br}$ (BrCHEM1, 0.72 \pm 0.01 ) and $\mathrm{OH}$ radical (OHCHEM, 0.71 \pm $0.02)$, which better reproduced the meridional profile of GEM concentration. The reaction with $\mathrm{O}_{3}(\mathrm{O} 3 \mathrm{CHEM})$ pro- vided poorer spatial correlation $(0.65 \pm 0.04)$ because it leveled the intercontinental GEM gradient. As mentioned earlier, $\mathrm{O}_{3}$ concentrations are considerably higher in the northern midlatitudes than in the Southern Hemisphere (Fig. S8 in the Supplement), leading to more intensive oxidation and decreased GEM levels in the Northern Hemisphere.

\subsection{Reactive mercury}

The oxidized $\mathrm{Hg}$ species composing RM originate in the atmosphere both from direct anthropogenic emissions and through oxidation of GEM in the gas phase, in the aqueous phase of cloud water, and in a heterogeneous manner at various atmospheric interfaces (Ariya et al., 2015). Therefore, simulating RM with contemporary models is a much more challenging task given the incomplete state of current knowledge of $\mathrm{Hg}$ atmospheric chemistry as well as the sparsity and uncertainty of measurements (Gustin et al., 2015). Figure 5 shows the global distributions of RM concentration in surface air as simulated by the models for the BASE case. The models predicted considerably different spatial RM concentration patterns. The concentrations were comparable in industrial regions, which were affected by direct anthropogenic emissions, but differed significantly in remote regions where the influence of emissions was weaker. Hence, the simulated patterns depended strongly on the chemical mechanisms and removal process parameterizations used. Indeed, the models that used $\mathrm{O}_{3}$ and/or $\mathrm{OH}$ oxidation chemistry in the BASE case (Figs. 5a, c, d) predicted elevated RM concentrations at low latitudes (the tropics and the equatorial zone) due to high concentrations of these photo-oxidants (mainly the $\mathrm{OH}$ radical) in these regions (see Fig. S9 in the Supplement). In 
(a)

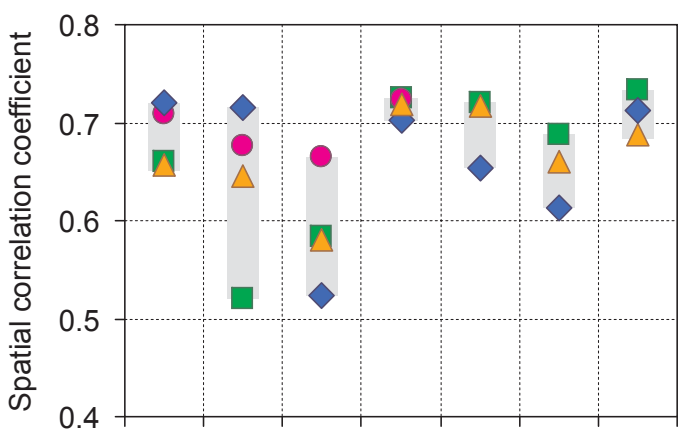

(b)

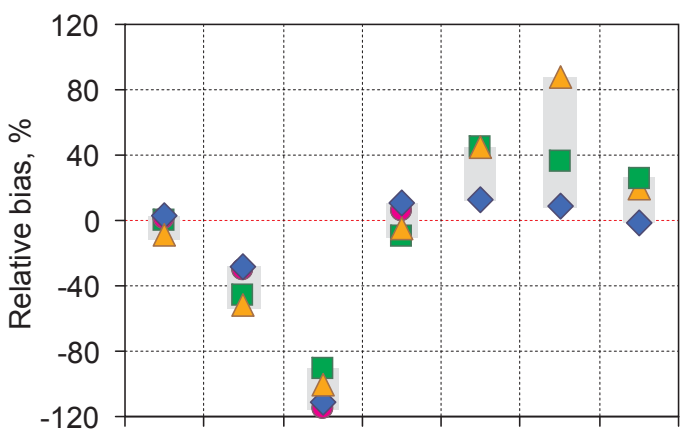

(c)

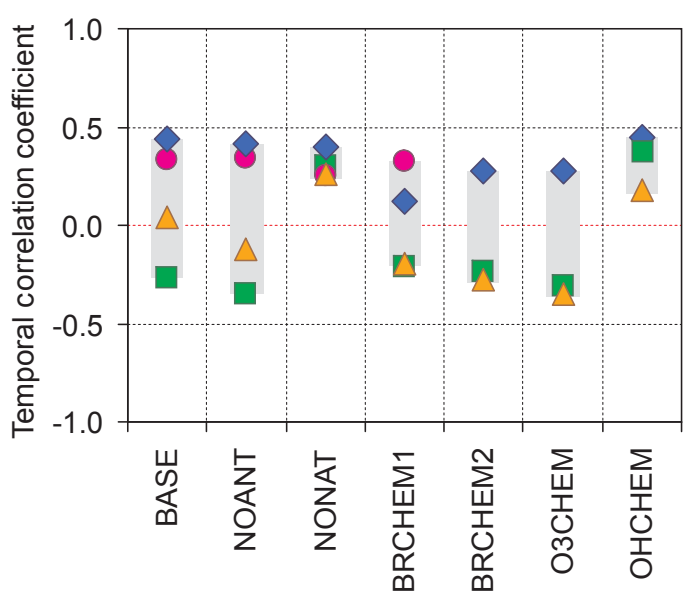

$\square$ GLEMOS • GEOS-Chem • GEM-MACH-Hg $\triangle$ ECHMERIT

Figure 4. Spatial correlation coefficient (a), relative bias (b), and temporal correlation coefficient (c) of simulated and observed GEM air concentration for different model experiments.

contrast, use of Br-derived chemistry (Fig. 5b) led to a spatial pattern with elevated RM concentrations in the polar regions, particularly in the Southern Hemisphere. This observation is in agreement with the spatial distribution of $\mathrm{Br}$ in the atmosphere (Fig. S7 in the Supplement). In addition, the model parameterization of dry deposition also considerably affected RM concentrations in surface air. Inclusion of effective RM removal in the marine boundary layer by sea-salt aerosols in GEOS-Chem (Holmes et al., 2010) resulted in lower RM concentrations over the oceans than those simulated by other models (Fig. 5b).
The scarcity of long-term RM observations did not permit reconstruction of reliable spatial trends on a global scale. Annual mean RM observations for the year under study are available only at nine sites in North America, two sites in Europe, one site in the Arctic, and two sites in the Southern Hemisphere (Fig. 1). Considering the short lifetime of RM in the atmosphere with respect to its deposition (Gustin et al., 2015; Ariya et al., 2015) this limited observational dataset cannot characterize spatial RM variation around the globe. Nevertheless, the measurements can be used to evaluate modeling results at particular locations. The models showed variable performance in reproducing measured values. The scatter plots of the model-to-measurement comparison shown in Fig. S3 in the Supplement demonstrate significantly poorer model agreement with observations than in the case of GEM. From 30 to $90 \%$ of the simulated values fell outside the range of agreement within a factor of 3 . In addition, there was a general tendency to overestimate observed concentrations. The level of overestimation varied among sites and among models and can be explained by a number of factors, including measurement uncertainties associated with losses due to interference of oxidants and incomplete capture of GOM (Lyman et al., 2010; Huang and Gustin, 2015; Gustin et al., 2015), incorrect emissions speciation (Zhang et al., 2012; Amos et al., 2012; Kos et al., 2013; Bieser et al., 2014), and the uncertainties of atmospheric chemistry (Weiss-Penzias et al., 2015; Ariya et al., 2015; Shah et al., 2016).

Figure 6 shows statistics for model-to-measurement comparisons of RM air concentration for different model experiments. As mentioned earlier, the models considerably overestimated the observed values in the BASE case simulation. Similar overestimation was observed by Kos et al. (2013) when simulating $\mathrm{Hg}$ oxidized forms in a series of model sensitivity runs. This observation was attributed to a significant extent to incorrect speciation of anthropogenic emissions, with a too-high proportion of oxidized $\mathrm{Hg}$ forms. This was also confirmed by the NoANT experiment in the current study, where zeroed-out anthropogenic emissions led to a significantly lower positive or even negative bias (Fig. 6a). To reduce the effect of this uncertainty in the current study, a modified speciation of emissions data was used for the model experiments focused on comparing chemical mechanisms, with all $\mathrm{Hg}$ emissions treated as GEM (Sect. 2.4). The overprediction of observed RM concentrations by a factor of 2.5 was also found by Weiss-Penzias et al. (2015) for a number of high- and mid-elevation sites and was found to be connected with the collection inefficiency of the $\mathrm{KCl}$ denuder used for the GOM measurements (Gustin et al., 2013). The models differed in their ability to reproduce the temporal variation in RM concentration (the correlation coefficient varied from -0.5 to 0.6 in the BASE case) (Fig. 6b). This variation was connected both with the different chemical mechanisms used in the standard model configurations (Table 1) and with deviations in model treatment of the removal processes responsible for dry and wet deposition. Ex- 
(a)

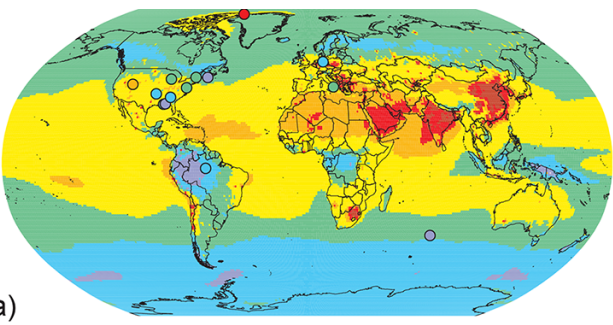

(c)

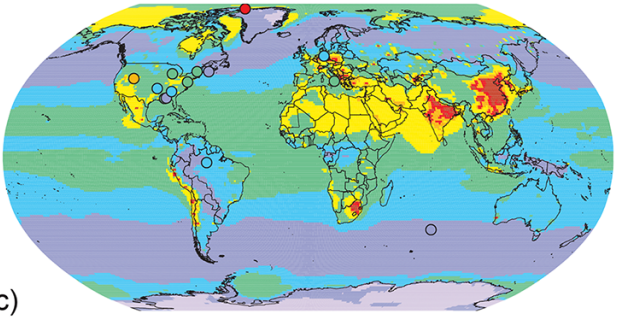

(b)

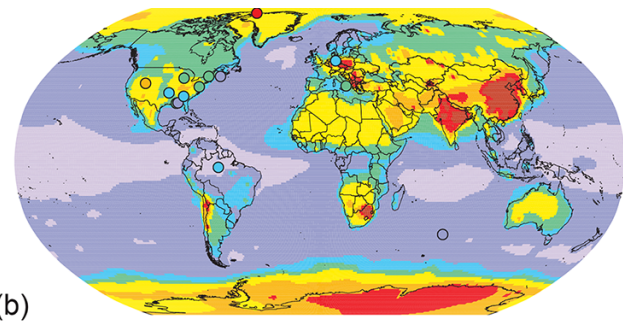

(d)

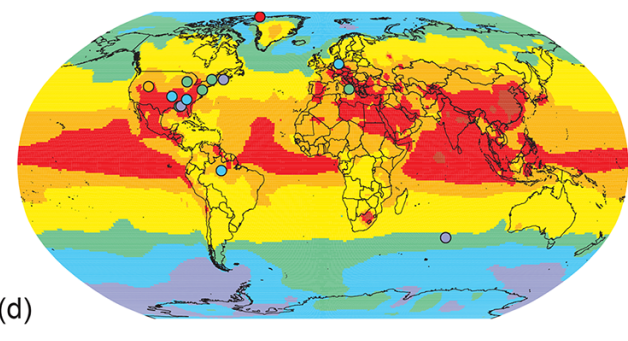

$\begin{array}{lllllllll}0 & 1 & 5 & 10 & 20 & 40 & 60 & 100 & \mathrm{pg} \mathrm{m}^{-3}\end{array}$

Figure 5. Spatial distribution of annual mean RM air concentration in 2013 simulated according to the BASE case by four global models: (a) GLEMOS, (b) GEOS-Chem, (c) GEM-MACH-Hg, and (d) ECHMERIT. Circles show observed values in the same color scale.

(a)

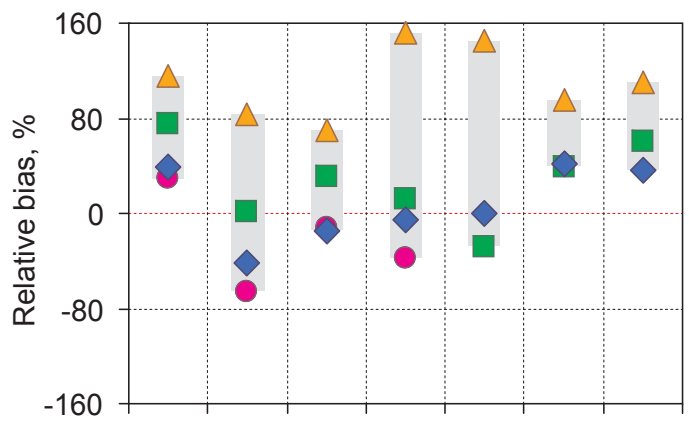

(b)

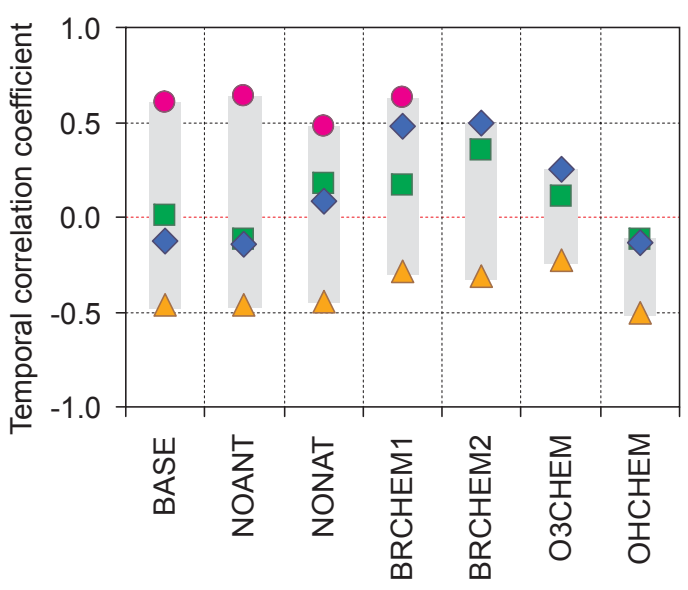

\section{GLEMOS • GEOS-Chem $\diamond$ GEM-MACH-Hg $\triangle$ ECHMERIT}

Figure 6. Relative bias (a) and spatial correlation coefficient (b) of simulated and observed annual mean RM air concentration for different model experiments. clusion of anthropogenic and natural/secondary emissions (NoANT and NoNAT) only slightly affected the temporal correlations of the modeling results with observations. However, it should be pointed out once again that the emissions inventory used for this study (AMAP/UNEP, 2013b) did not resolve the intra-annual variability of anthropogenic emissions. Hence, one can expect a stronger effect of anthropogenic emissions on RM temporal variation. Among the chemical mechanisms, the best correlations between modeled and observed values were obtained for reactions with $\mathrm{Br}$ (BrCHEM1 and BrCHEM2), followed by the $\mathrm{OH}$ oxidation mechanism (OHCHEM). Inclusion of the reaction with $\mathrm{O}_{3}$ led to a negative correlation with observations.

A more detailed analysis of chemical oxidation mechanisms is illustrated in Fig. 7 in terms of simulated and observed RM / GEM ratios. Indeed, atmospheric RM originates either from direct emissions from anthropogenic sources or as a product of GEM oxidation in the atmosphere (Selin, 2009; Travnikov, 2012; Kos et al., 2013; Ariya et al., 2015). Hence, in the immediate vicinity of emission sources, the $\mathrm{RM} / \mathrm{GEM}$ ratio reflects the speciation of $\mathrm{Hg}$ emissions, whereas in remote regions far away from any emissions, it largely quantifies the oxidative capability of the atmosphere. Given the short lifetime of RM in the atmosphere with respect to deposition, the influence of direct emissions on the RM / GEM ratio should quickly weaken with distance from sources. Following the methodology suggested by Kos et al. (2013) the sites used for the following analysis were classified with respect to their remoteness from significant emission sources, based on the model sensitivity run with $\mathrm{Hg}$ atmospheric chemistry turned off. The simulated RM concentrations showed (Fig. S6 in the Supplement) that all the 

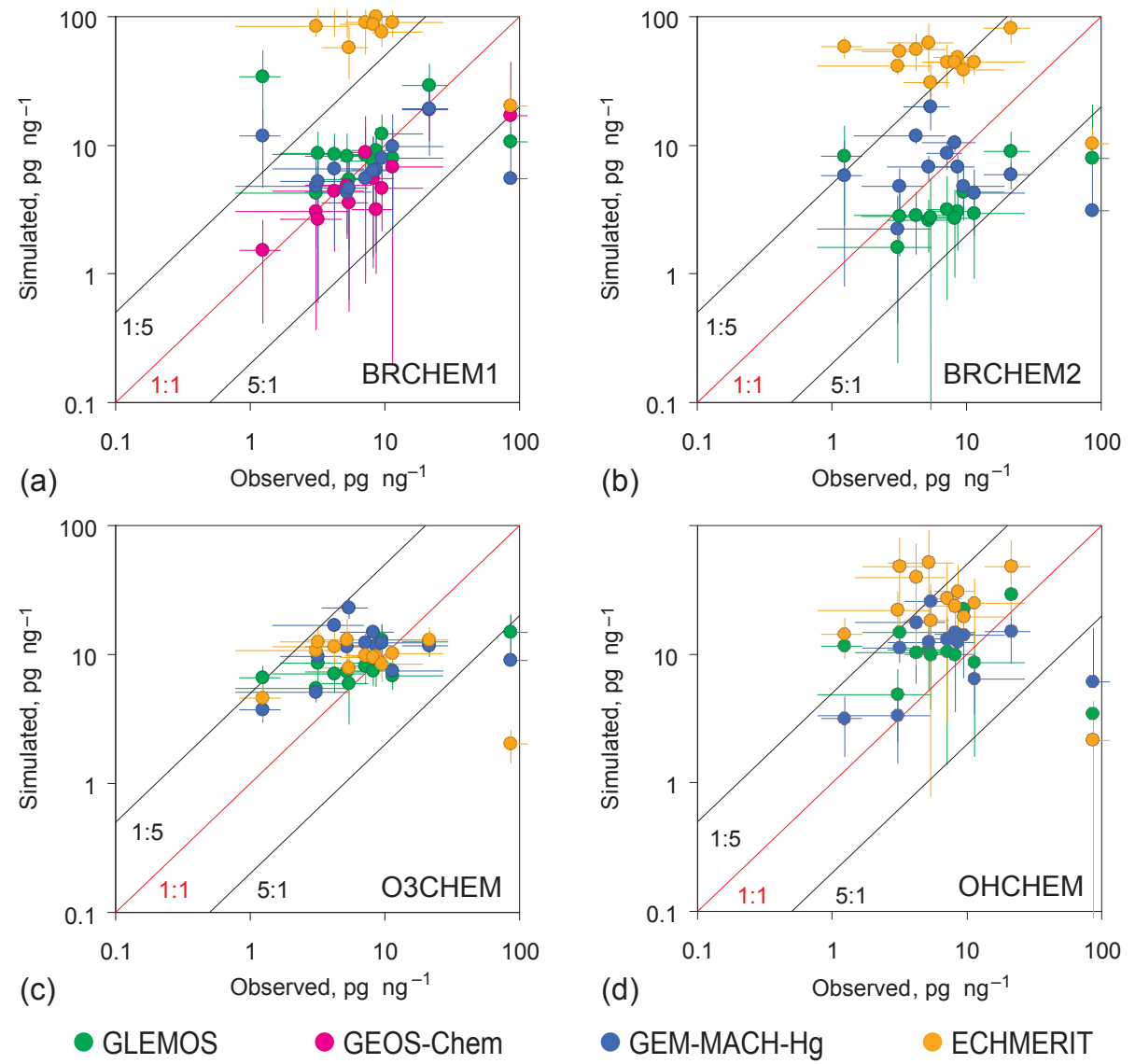

- GEM-MACH-Hg $\quad$ ECHMERIT

Figure 7. Scatter plots of simulated vs. observed ratios of annual mean RM concentration to GEM concentration in 2013 for different model experiments: (a) BrCHEM1, (b) BrCHEM2, (c) O3CHEM, and (d) OHCHEM. Whiskers show standard deviation of monthly mean simulated and observed values. Dotted red line depicts the $1: 1$ ratio; dotted black lines show deviation by a factor of 5 .

selected sites (except one) could be classified as being far from sources $\left(0-30 \mathrm{pg} \mathrm{m}^{-3}\right)$. This observation agrees with the characteristics of the North American sites as given by Lan et al. (2012). The only site that was probably directly affected by anthropogenic emissions was Waldhof, Germany (Weigelt et al., 2013). Nevertheless, because both the mean levels and the seasonal variation of RM concentrations measured at this site did not differ significantly from other sites, it was retained in the dataset. However, it should be noted that this analysis essentially depended upon the emissions data used and could translate any data uncertainties into the classification results.

Figure 7 shows a comparison of simulated and observed annual mean RM / GEM ratios for different chemical mechanisms. The whiskers show the standard deviation of monthly mean simulated and observed values. It should be pointed out that the observed values of RM / GEM (1-10 $\mathrm{pg} \mathrm{ng}^{-1}$ ) correspond to the background conditions of the continental boundary layer and are considerably lower than those from mountain sites analyzed by Weiss-Penzias et al. (2015) (10$100 \mathrm{pg} \mathrm{ng}^{-1}$ ). Exceptions are the site at Alert, Canada, located in the High Arctic $\left(86 \mathrm{pg} \mathrm{ng}^{-1}\right)$ and the elevated site at
Salt Lake City, United States $\left(21 \mathrm{pg} \mathrm{ng}^{-1}\right)$. It is interesting to note that the other elevated site (Longobucco, Italy) did not show similarly increased RM / GEM values $\left(9.5 \mathrm{pg} \mathrm{ng}^{-1}\right)$. As shown in Fig. 7, the best qualitative agreement between model and measurements was found in the BrCHEM1 experiment with the $\mathrm{Br}$ chemistry and one of the $\mathrm{Br}$ concentration datasets (Fig. 7a). Three of the four models demonstrated good performance in this experiment, reproducing observations at most sites with a deviation within a factor of 3 . The fourth model (ECHMERIT) significantly overestimated the observed values, which was also typical of the other model experiments (except for O3CHEM). This overestimation was caused not by the chemistry used but by underestimation of wet scavenging as shown below. Use of $\mathrm{Br}$ chemistry with the other $\mathrm{Br}$ concentration dataset (BrCHEM2) led to less consistent results (Fig. 7b). The RM / GEM ratios simulated by the models varied from moderate underestimation to overestimation of observed values. The inter-model differences could have been caused both by discrepancies in removal process formulation and by particular implementations of the $\mathrm{Br}$ chemical mechanism (Table 1). Somewhat similar results were obtained in the experiment with $\mathrm{OH}$ chemistry 
(OHCHEM, Fig. 7d). The deviations between modeled and measured RM / GEM were mostly within a factor of 5, and the models tended to overestimate the observed values. Application of the $\mathrm{O}_{3}$-initiated chemistry led to very consistent results (O3CHEM, Fig. 7c). The models also somewhat overestimated the measured RM/GEM ratios, with minimum scattering of modeling results. However, the models tended to underestimate considerably the intra-annual variation of monthly values, as shown by the whiskers. None of the chemical mechanisms could reproduce the high annual RM / GEM ratios (above $80 \mathrm{pg} \mathrm{ng}^{-1}$ ) observed at the Arctic site Alert, Canada (Fig. 7a-c). These high annual values are connected with intensive $\mathrm{Hg}$ oxidation during springtime AMDEs. Analysis of specific processes typical of the polar regions is beyond the scope of this paper. A discussion of the results of the study that focused on the polar regions can be found elsewhere (Angot et al., 2016).

More insight into the effects of different chemical mechanisms can be obtained by analyzing RM / GEM seasonal variation. Figure 8 shows both measured and simulated variation in the monthly mean RM / GEM ratio averaged over selected sites. Because seasonal variation of both RM and GEM differs in the Northern and Southern hemispheres and because most of the study sites are located in North America and Europe, two sites situated north of the Equator were selected for this purpose. In addition, the Arctic site (Alert) and the two high-elevation sites (Salt Lake City and Longobucco) were excluded to avoid the effects of specific conditions in the polar regions and the free troposphere, respectively. Hence, the collection of sites characterizes the seasonality of $\mathrm{Hg}$ oxidation in the continental boundary layer in northern temperate latitudes. The observed values demonstrated pronounced seasonal changes in RM / GEM, with a maximum in March and a minimum in September (Fig. 8). Similar seasonal variations of $\mathrm{Hg}$ oxidized forms at background sites were observed in previous studies (Poissant et al., 2005; Sigler et al., 2009; Nair et al., 2012; Weigelt et al., 2013). The chemical oxidation mechanisms differed in their ability to reproduce the observed seasonal variation.

Use of $\mathrm{Br}$ chemistry with both $\mathrm{Br}$ concentration datasets (BrCHEM1 and BrCHEM2) provided the best agreement with measurements. Three of the four models (GEOS-Chem, GEM-MACH-Hg, and GLEMOS) reproduced the maximum RM / GEM ratios during the spring months (Fig. 8a and b). High levels of oxidized $\mathrm{Hg}$ in spring are evidently caused by high $\mathrm{Br}$ concentrations in both the free troposphere and the boundary layer in the Northern Hemisphere (Fig. S10 in the Supplement). However, only GEOS-Chem reproduced correctly the time of the maximum in March. Two other models moved the highest RM / GEM ratio to April and May. This discrepancy can be explained by partitioning the GEM oxidation products. GEOS-Chem is the only model that used dynamic gas-particle partitioning of RM (Table 1). This meant that oxidized $\mathrm{Hg}$ originated from GEM oxidation was dynamically fractionated between GOM and PBM. This equi- librium is sensitive to air temperature shifting to GOM under warmer conditions (Amos et al., 2012). Furthermore, GOM is more efficiently removed from the atmosphere than PBM by both precipitation and surface uptake. This phenomenon leads to higher deposition and lower RM concentrations in late spring (April and May). Two other models predicted a fixed share of the products of GEM oxidation by $\mathrm{Br}$, thus missing changes in RM concentration during the season. The fourth model (ECHMERIT) predicted the highest ratios during late summer independently of the chemical mechanism used, a phenomenon that was determined by meteorological conditions and removal processes. In particular, the model simulated extremely low precipitation in late summer and early fall (Fig. 12i and j). This led to significant underestimation of wet RM removal and ultimately to overestimation of oxidized $\mathrm{Hg}$ concentrations during this period.

Model simulations with $\mathrm{OH}$ chemistry (OHCHEM) predicted maximum RM/GEM ratios during the summer months (Fig. 8d) in accordance with the seasonal variation of $\mathrm{OH}$ concentration, which was also highest in summer (Fig. $\mathrm{S} 12$ in the Supplement). Use of the $\mathrm{O}_{3}$-initiated chemistry did not lead to significant variation of $\mathrm{Hg}$ oxidation during the year (Fig. 8c).

\subsection{Wet deposition}

Wet deposition is one of the major removal mechanisms responsible for $\mathrm{Hg}$ exchange between the atmosphere and the Earth's surface (Travnikov, 2012; Swartzendruber and Jaffe, 2012). It is largely determined by precipitation events on the one hand and by availability of soluble $\mathrm{Hg}$ forms in the atmosphere on the other. Given the poor solubility of GEM (Clever et al., 1985; Ariya et al., 2015), Hg wet deposition consists mostly of scavenging of $\mathrm{Hg}$ oxidized forms (GOM and PBM). Therefore, $\mathrm{Hg}$ concentration in precipitation and ultimately wet deposition flux largely depends upon three factors: direct emissions of oxidized $\mathrm{Hg}$ from anthropogenic sources, $\mathrm{Hg}$ oxidation in the atmosphere, and precipitation amount. Figure 9 shows the spatial patterns of annual mean $\mathrm{Hg}$ wet deposition as simulated by the four models according to the BASE case. Available measurements are also shown in the same color palette. Generally, the simulated deposition maps have similar spatial distributions, reflecting the influence of global precipitation patterns and major emission regions. High deposition fluxes are characteristic of Asia, Europe, and North America, where significant anthropogenic sources are located, as well as of regions with intensive precipitation (e.g., the Intertropical Convergence Zone). The lowest wet deposition fluxes occurred in dry regions (e.g., in northern Africa, Greenland, and Antarctica). Divergences among the modeling results could be mostly explained by the different chemical mechanisms used by the models in the BASE case. For instance, GEOSChem predicted elevated wet deposition in the high latitudes of the Southern Hemisphere, where high Br concentrations 

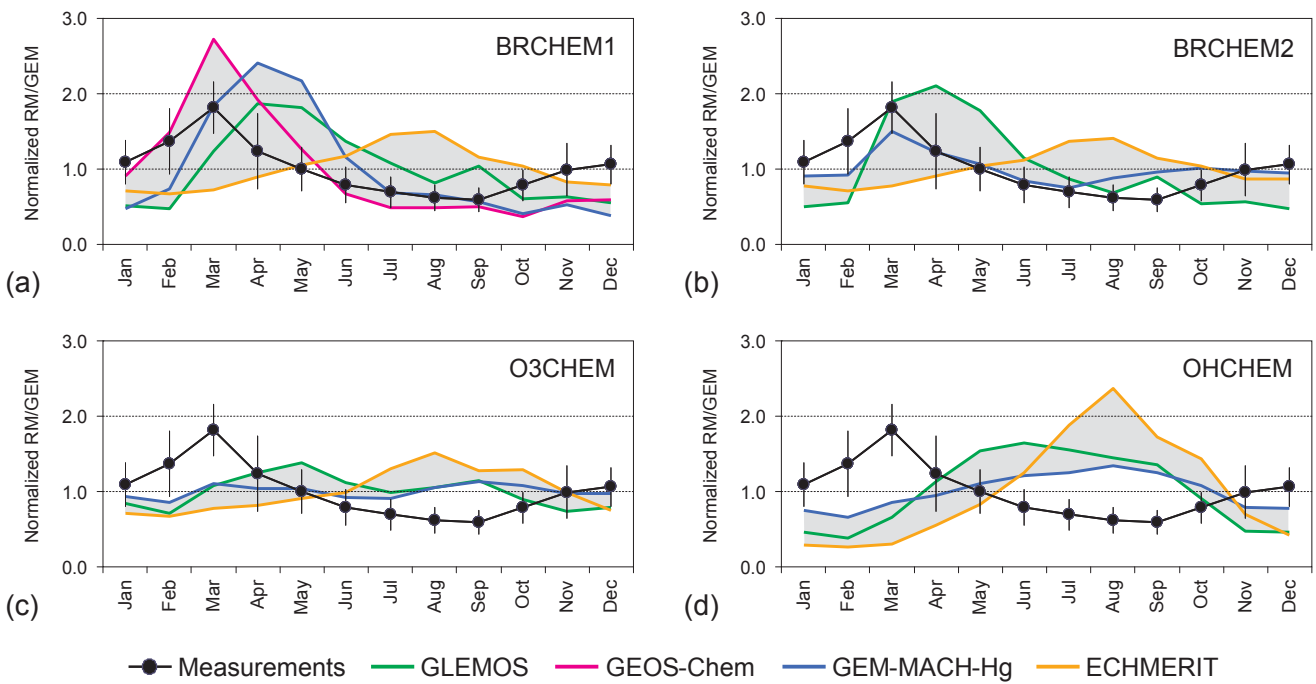

Figure 8. Normalized seasonal variation of monthly ratio of annual mean RM concentration to GEM concentration. Black line with dots shows observations averaged over selected sites (whiskers are standard deviation). Colored lines present model simulations averaged over the same sites for different model experiments: (a) BrCHEM1, (b) BrCHEM2, (c) O3CHEM, and (d) OHCHEM.

(Fig. S7 in the Supplement) caused intensive GEM oxidation in the atmosphere (Fig. 9b). In contrast, significant deposition fluxes were simulated in the High Arctic by GEMMACH-Hg (Fig. 9c) because parameterizations of physical and chemical processes occurring during AMDEs were used. The models agreed relatively well with available long-term observations of $\mathrm{Hg}$ wet deposition. Model-to-measurement deviations commonly did not exceed a factor of 2 (Fig. S4 in the Supplement). However, it should be noted that available observations of $\mathrm{Hg}$ wet deposition are still mostly restricted to two regions: North America and Europe. Only a few measurements are available in other regions, particularly in the Southern Hemisphere.

Figure 10 shows statistics of the comparison of simulated and observed wet deposition fluxes. Results of the BASE case simulation are characterized by significant temporal correlation with measurements (0.4-0.6) and some slight bias $( \pm 40 \%)$ that varies among models. Direct anthropogenic emissions of oxidized $\mathrm{Hg}$ contributed considerably to wet deposition, and hence their elimination (NoANT) resulted in a noticeable deposition decrease characterized by negative bias. In contrast to anthropogenic emissions, natu$\mathrm{ral} / \mathrm{secondary}$ sources emit $\mathrm{Hg}$ mostly as GEM. Nevertheless, turning off natural/secondary emissions (NoNAT) also led to a substantial decrease in wet deposition, indicating their indirect effect through GEM oxidation on soluble $\mathrm{Hg}$ forms, with subsequent scavenging by precipitation. The temporal correlation of wet deposition was not sensitive to emission changes. This is not surprising because the anthropogenic emissions inventory used in this study did not contain information on temporal emissions variation. Oxidation chemistry considerably affected both the general level and the temporal variation of $\mathrm{Hg}$ wet deposition. The Br oxidation mechanism provided a relatively high correlation with observations, but the results for the two $\mathrm{Br}$ concentration datasets (BrCHEM1 and BrCHEM2) differed widely in terms of relative bias. The highest correlation was obtained for $\mathrm{OH}$ oxidation chemistry (OHCHEM). Note that, unlike the other models used for this study, ECHMERIT is based on the ECHAM climate model, which is expected to reproduce actual weather behavior, in particular precipitation events, over a relatively longer temporal period and a wider area than the other models, but may diverge on shorter timescales and over smaller regional areas (see, for example, Angálil et al., 2016). Because simulated $\mathrm{Hg}$ wet deposition is largely driven by model-generated precipitation, the results of the climate-based ECHMERIT model can be significantly biased with regard to other wet deposition models and observations (Fig. 10).

Similarly to $\mathrm{RM}$ concentration, $\mathrm{Hg}$ wet deposition is strongly determined by atmospheric oxidation chemistry (Selin and Jacob, 2008; Kos et al., 2013). Therefore, analysis of wet deposition can also be used to evaluate the chemical mechanisms of $\mathrm{Hg}$ oxidation in the atmosphere. Unlike near-surface RM observations, wet deposition measurements characterize processes occurring in the free troposphere because scavenging of soluble $\mathrm{Hg}$ takes place both in the cloud environment and below clouds along the whole precipitation pathway. Figure 11 shows a comparison of simulated and observed wet deposition fluxes for different model experiments. Both measured and simulated values are averaged over different groups of sites, including seven groups in North America following the latitudinal ranges suggested by Selin and Jacob (2008), three groups in Europe (southern Europe, western Europe, and northern Europe), and one group per region in Asia, Australia, and the Indian Ocean (see Table S3 in the Supplement). Note that the highest observed 

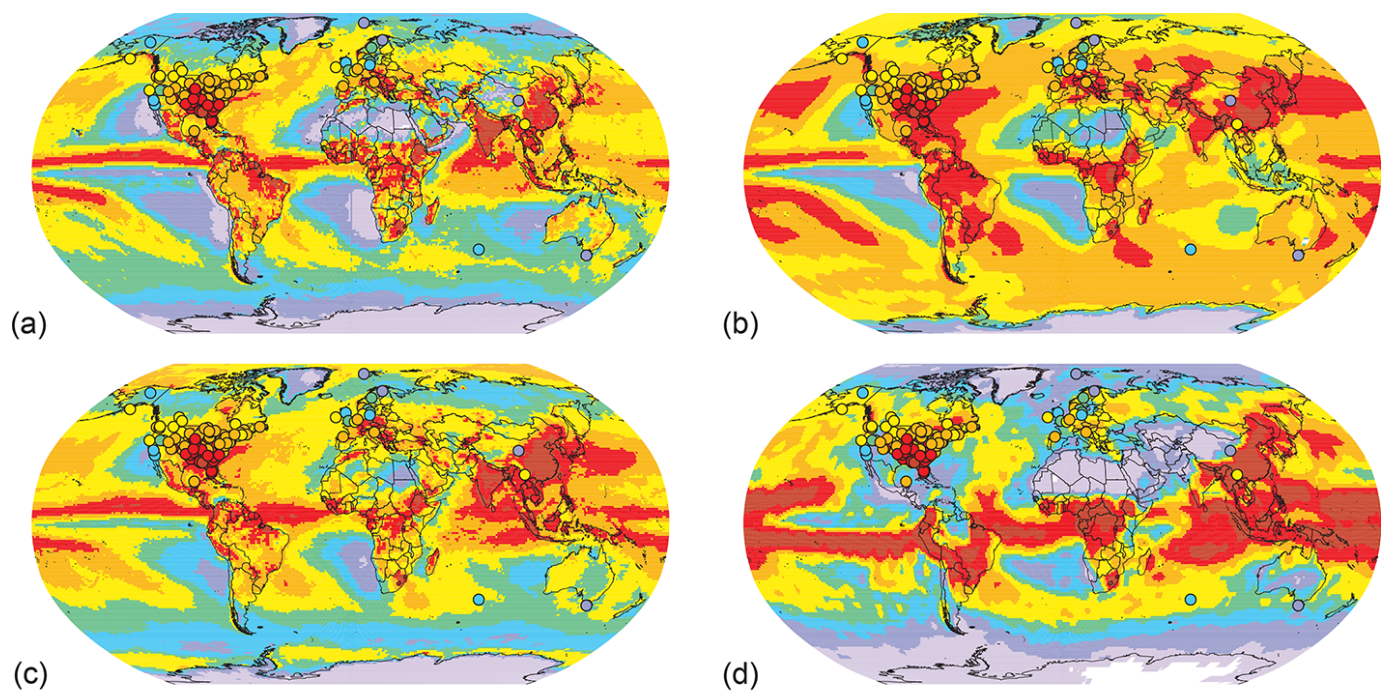

(b)

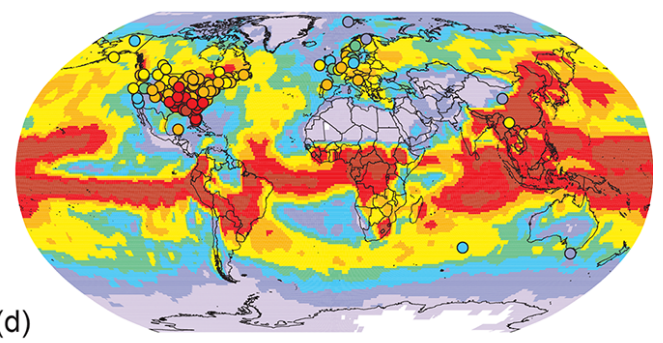

$\begin{array}{llllllll}0 & 2 & 5 & 8 & 12 & 20 & 30 & 50 \\ \mathrm{ng} \mathrm{m}^{-2} \text { day }^{-1}\end{array}$

Figure 9. Spatial distribution of wet deposition flux in 2013 simulated according to the BASE case by four global models: (a) GLEMOS, (b) GEOS-Chem, (c) GEM-MACH-Hg, and (d) ECHMERIT. Circles show observed values in the same color scale.

(a)

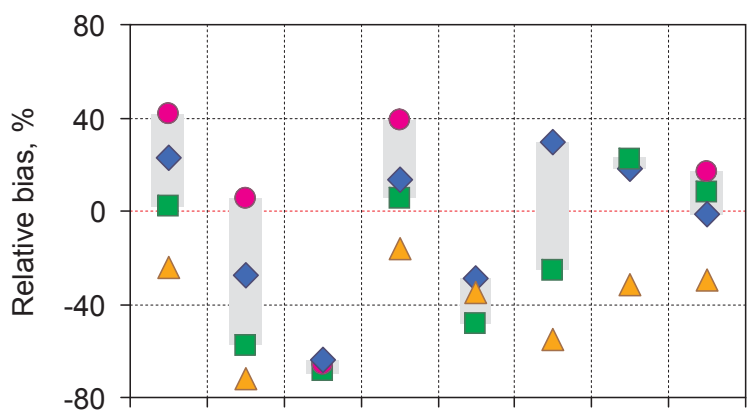

(b)

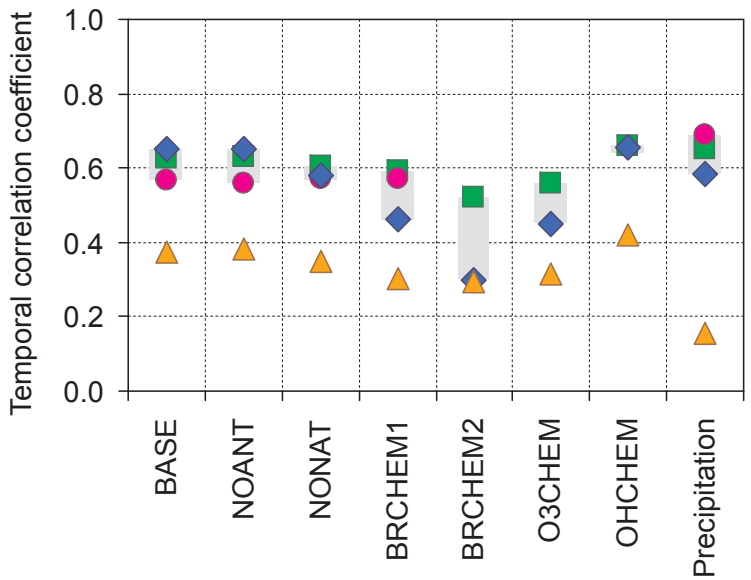

n GLEMOS • GEOS-Chem • GEM-MACH-Hg $\triangle$ ECHMERIT

Figure 10. Relative bias (a) and spatial correlation coefficient (b) of simulated and observed annual mean wet deposition flux for different model experiments. wet deposition values (30-45 $\mathrm{ng} \mathrm{m}^{-2}$ day $\left.^{-1}\right)$ are associated with the southern United States, whereas the lowest values (below $10 \mathrm{ng} \mathrm{m}^{-2} \mathrm{day}^{-1}$ ) are characteristic of sites located in East Asia and in the Southern Hemisphere (see Fig. 9). As shown in Fig. 11, simulations with the Br oxidation mechanism and the first set of $\mathrm{Br}$ concentration data (BrCHEM1) satisfactorily reproduced observations (Fig. 11a). The models agreed relatively well with each other, and the model-tomeasurement deviations generally did not exceed a factor of 2. However, all models overpredicted low deposition fluxes at Asian and southern sites. The overestimation of $\mathrm{Hg}$ wet deposition at two high-altitude Asian sites (Mt. Waliguan and Mt. Ailao) can be connected with the inability of the coarse-spatial-resolution global models to reproduce complex meteorological conditions in mountain regions. Overprediction at southern sites (Cape Grim and Amsterdam Island) can be explained by the very high $\mathrm{Br}$ concentrations predicted by the first dataset at temperate latitudes in the Southern Hemisphere (Fig. S7 in the Supplement). Use of the same mechanism with the other $\mathrm{Br}$ dataset led to considerably lower wet deposition levels (Fig. 11b) due to use of much lower $\mathrm{Br}$ concentrations, particularly in the free troposphere (Fig. S7 in the Supplement). Hence, uncertainties in the available estimates of $\mathrm{Br}$ atmospheric concentration strongly affected simulation results for $\mathrm{Hg}$ cycling in the atmosphere. Model simulations with the $\mathrm{O}_{3}$ and $\mathrm{OH}$ oxidation mechanisms (O3CHEM and OHCHEM) provided reasonable agreement between modeling results and measurements (Fig. 11c and d). Two of the three models (GEMMACH-Hg and GLEMOS) demonstrated fairly good correlations with observations, but again tended to overestimate lower observed values. The $\mathrm{OH}$ oxidation chemistry pro- 

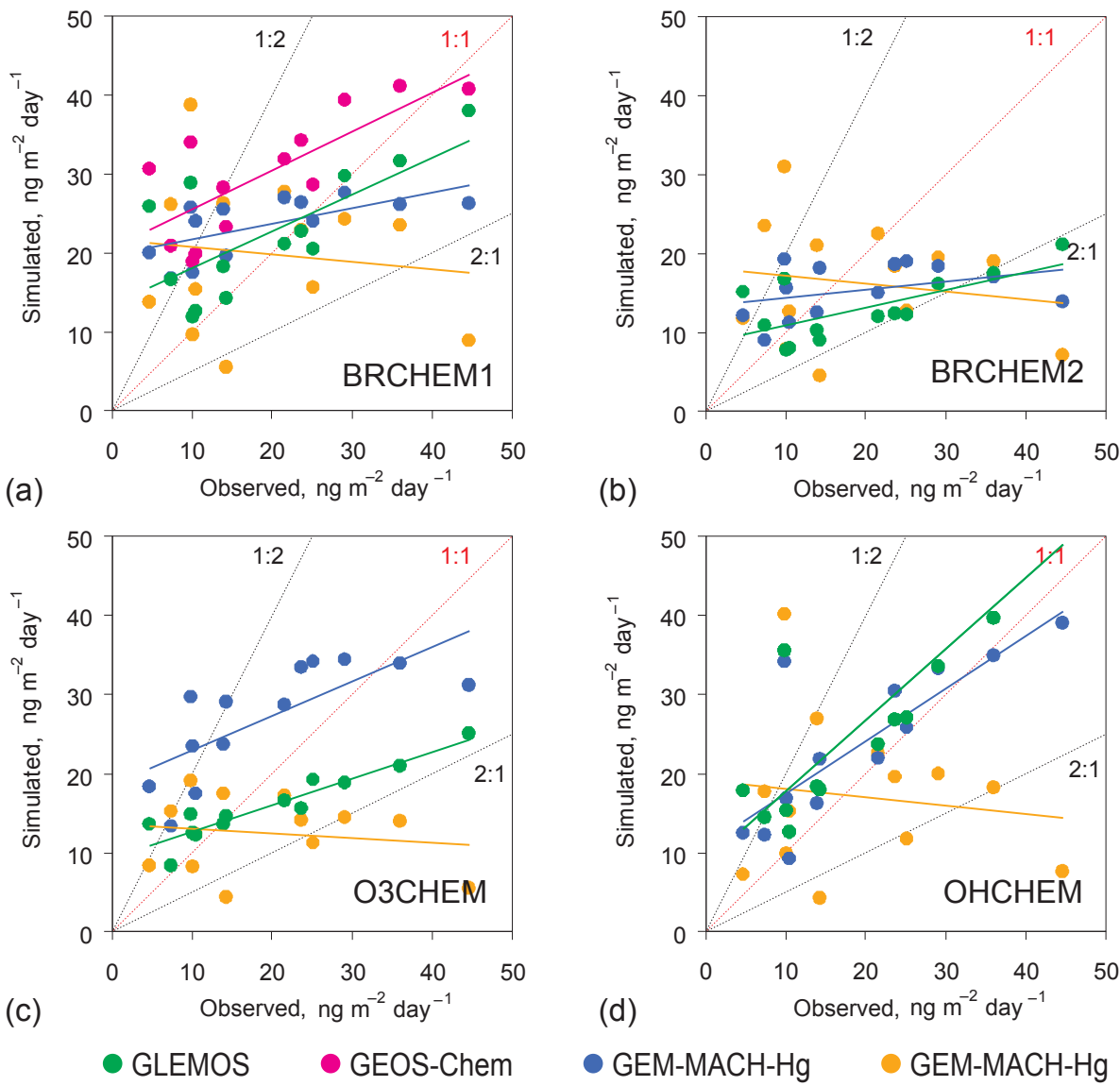

GEM-MACH-Hg GEM-MACH-Hg

Figure 11. Scatter plots of simulated vs. observed annual mean wet deposition flux in 2013 averaged over different territorial groups of sites (see Table S3 in the Supplement) for different model experiments: (a) BrCHEM1, (b) BrCHEM2, (c) O3CHEM, and (d) OHCHEM. Solid lines depict linear approximation. Dotted red line depicts the $1: 1$ ratio; dotted black lines show deviation by a factor of 2 .

vided somewhat better agreement in terms of the slope of the regression line, which was closer to the reference $1: 1$ line, indicating better reproduction of both low and high wet deposition fluxes. The third model (ECHMERIT) showed wider divergence of simulation results because of the uncertainties described above in its reproduction of precipitation events in some locations. In particular, these uncertainties led to significant underestimation of $\mathrm{Hg}$ wet deposition in the southern part of North America.

More information on the performance of different chemical mechanisms can be obtained by analyzing seasonal wet deposition patterns. Because most available wet deposition measurements are obtained at sites in North America and Europe, further discussion will focus on these two regions. Figure 12 shows a comparison of modeled and measured temporal variation of monthly mean wet deposition flux averaged over sites in North America and Europe. The monthly fluxes were normalized by the annual average value to remove absolute differences among the models and reveal peculiarities of seasonal changes. The observations exhibit a pronounced seasonal cycle, with a maximum in summer and a minimum during the cold season (winter and early spring). Similar seasonal variations have been reported in previous studies (Guentzel et al., 2001; Keeler et al., 2005; Choi et al., 2008; Prestbo and Gay, 2009; Sprovieri et al., 2017). Sprovieri et al. (2017) attributed these seasonal changes to variations in meteorological conditions (mainly precipitation amount), more effective $\mathrm{Hg}$ scavenging by rain compared to snow, and changes in availability of soluble $\mathrm{Hg}$. As shown in Fig. 12i and j, precipitation amounts measured in North America and Europe do not reveal a similar seasonality to explain the intra-annual variation of wet deposition. Seasonal variation of precipitation amounts in North America exhibits a similar pattern, with a maximum in summer and a minimum in winter, but the amplitude of the variation is much less than that of wet deposition. Average precipitation amounts in Europe do not show an evident seasonal pattern. Note that one of the four models (ECHMERIT) failed to reproduce the seasonal cycle of precipitation amounts in North America and Europe for the reasons mentioned previously. Because precipitation variation directly affects seasonal variation of $\mathrm{Hg}$ wet deposition, the simulation results 
North America (99 sites)
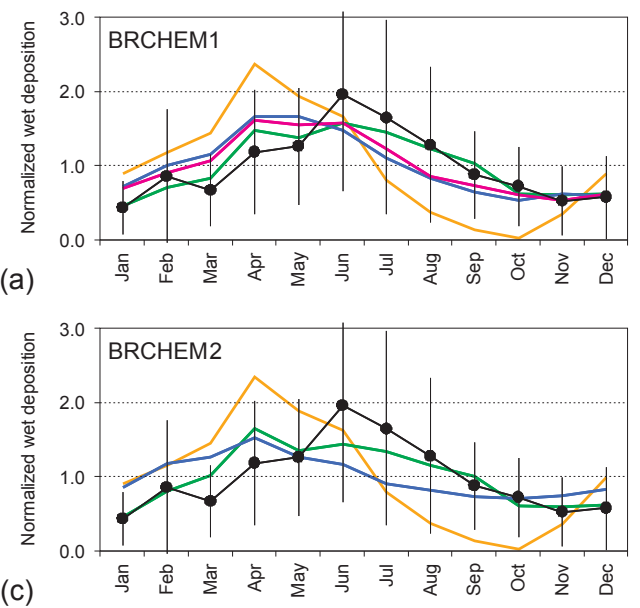

(c)
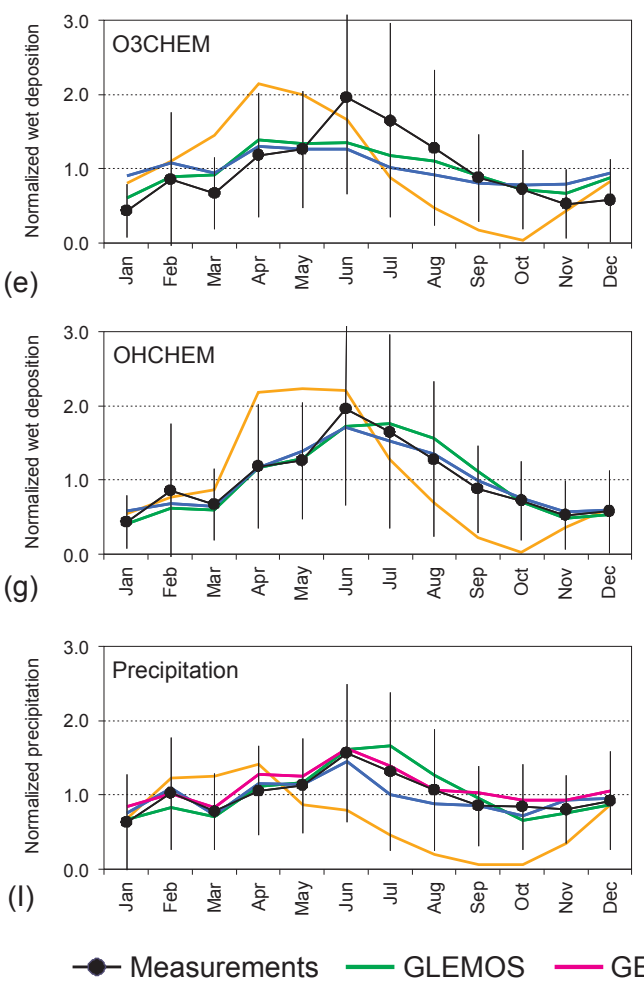

Europe (14 sites)
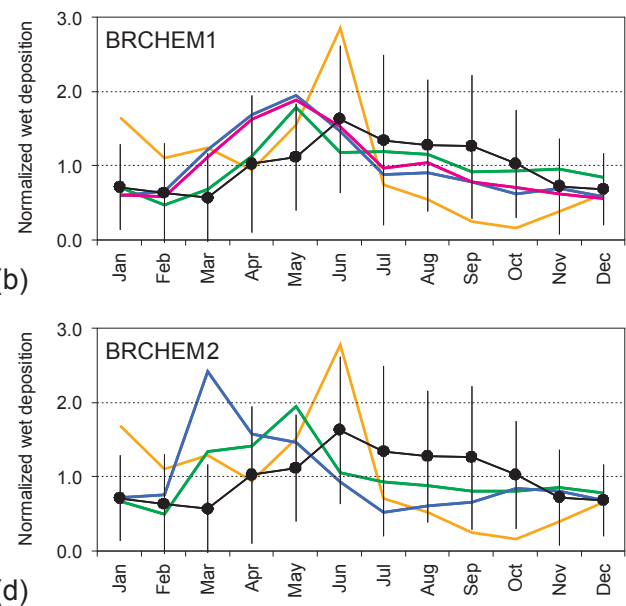

(d)

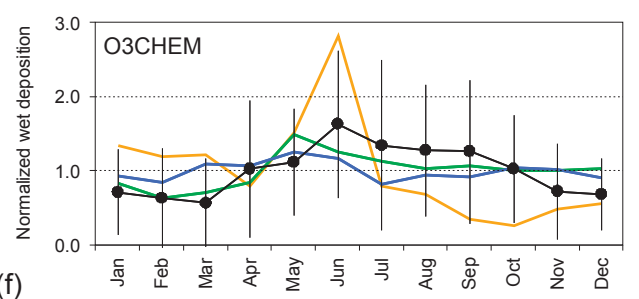

(h)
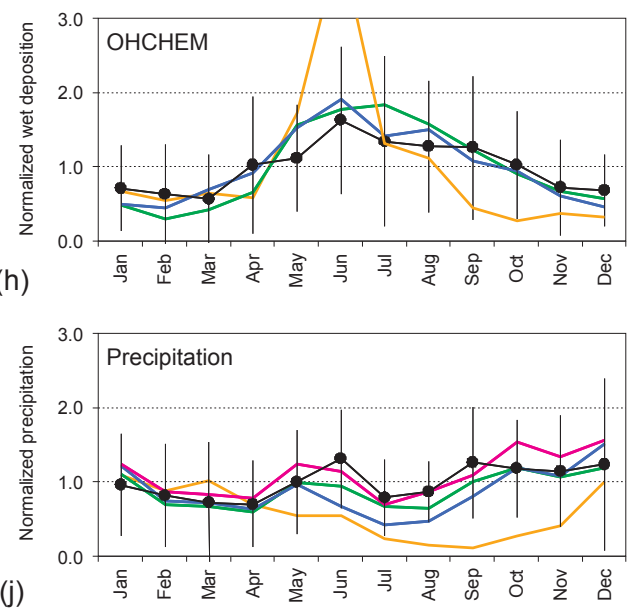

(j)

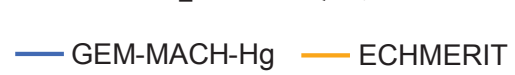

Figure 12. Normalized seasonal variation of monthly mean wet deposition flux in North America (left column) and Europe (right column). Black line with dots shows observations averaged over all sites in the regions (whiskers are standard deviation). Colored lines present model simulations averaged over the same sites for different model experiments: (a, b) BrCHEM1, (c, d) BrCHEM2, (e, f) O3CHEM, and (g, h) OHCHEM. Seasonal variations of precipitation amount in North America and Europe are also shown in panels (i) and (j), respectively.

from this model were not used when analyzing the performance of chemical mechanisms. However, the results themselves are shown in Fig. 12 for completeness. Availability of soluble $\mathrm{Hg}$ in the free troposphere depends strongly on oxidation chemistry. Therefore, different chemical mechanisms should affect the seasonality of wet deposition differently. Indeed, both model runs with the Br oxidation chemistry (BrCHEM1 and BrCHEM2) predicted a maximum in wet deposition during the spring months instead of in summer (Fig. 12a-d), following the seasonal variation of $\mathrm{Br}$ concentration in the atmosphere (Fig. S10 in the Supplement). Simulations with $\mathrm{O}_{3}$-initiated chemistry (O3CHEM) provided a much lower seasonality of deposition flux (Fig. 12e-f). In contrast, use of $\mathrm{OH}$ chemistry (OHCHEM) reproduced faithfully the observed seasonal variation of wet deposition in both study regions (Fig. 12g-h). Similar results were ob- 
tained by other researchers. Selin and Jacob (2008) simulated $\mathrm{Hg}$ wet deposition over the United States using combined $\mathrm{OH} / \mathrm{O}_{3}$ oxidation chemistry and successfully reproduced the measured seasonal variation. They attributed the summer maximum in the northeast to GEM photochemical oxidation and to inefficient scavenging by snow in winter. Holmes et al. (2010) compared the $\mathrm{Br}$ mechanism with the $\mathrm{OH} / \mathrm{O}_{3}$ mechanism for simulating the $\mathrm{Hg}$ global cycle. They found that the $\mathrm{OH} / \mathrm{O}_{3}$ chemistry better simulated the southeast $\mathrm{Hg}$ wet deposition summer maximum. It was postulated that the maximum reflected scavenging of GOM from the free troposphere by deep convection. Kos et al. (2013) also performed a number of sensitivity runs with different chemical process parameterizations and showed that the $\mathrm{OH}$ oxidation chemistry improved simulation of the seasonal cycle of wet deposition in North America. Considering that $\mathrm{Hg}$ wet deposition is largely defined by GEM oxidation (Selin and Jacob, 2008), a significant effect of $\mathrm{OH}$-initiated chemistry on $\mathrm{Hg}$ oxidation in the free troposphere can be expected. Moreover, when comparing this conclusion with the results presented in Sect. 3.2, where it was shown that the seasonal dynamics of the RM / GEM ratio observed at ground-based sites is dominated by Br oxidation chemistry, one can assume the possibility of different $\mathrm{Hg}$ oxidation mechanisms occurring concurrently in different parts of the atmosphere.

\section{Conclusions}

The study presented here provides a complex analysis of the processes governing $\mathrm{Hg}$ cycling in the atmosphere, involving both measured data from ground-based sites and application of chemical transport models. A variety of long-term GEM and RM concentration measurements as well as wet deposition flux readings have been compiled from different global and regional monitoring networks. Four contemporary global-scale $\mathrm{Hg}$ transport models were used, both in their state-of-the-art configurations and for a number of numerical experiments aimed at evaluation of particular processes. Results of the model simulations were evaluated against measurements. The models predicted similar global spatial GEM concentration patterns in near-surface air. The modelto-model difference in simulated GEM concentrations did not exceed $\pm 20 \%$ and agreed with observed values within $\pm 30 \%$. Nevertheless, there were pronounced distinctions among the spatial patterns simulated by different models, which resulted from deviations in the parameterizations of physical and chemical processes. All four models reproduced the observed GEM concentration decrease from the Northern to the Southern hemispheres. Analysis revealed that the interhemispheric gradient is largely formed by the spatial distribution of anthropogenic emissions that prevails in the Northern Hemisphere. The contributions of natural and secondary emissions enhanced the south-to-north gradient, but their effect was less significant. Simulations with different chemi- cal mechanisms provided somewhat different spatial GEM concentration patterns in surface air. Higher spatial correlations were obtained for the oxidation reactions with $\mathrm{Br}$ and $\mathrm{OH}$ radical, enabling better reproduction of the meridional GEM concentration profile. The reaction with $\mathrm{O}_{3}$ provided poorer spatial correlation because it leveled the intercontinental GEM gradient.

Model simulation of RM is a much more challenging task because of incomplete current knowledge of $\mathrm{Hg}$ atmospheric chemistry and the scarcity and uncertainty of measured data. The models differed considerably in their predictions of spatial and temporal RM concentration patterns. The simulated RM levels were comparable in industrial regions, which are affected by direct anthropogenic emissions, but differed significantly in remote regions where the influence of emissions is weaker. Hence, the simulated patterns depended strongly on the chemical mechanisms and removal process parameterizations used. Model-to-measurement comparisons demonstrated significantly poorer model agreement with observations than in the case of GEM. From 30 to $90 \%$ of the simulated values fell beyond the agreement range within a factor of 3. In addition, there was a general tendency to overestimate observed RM concentrations, which can be attributed to incorrect speciation of $\mathrm{Hg}$ emissions, the uncertainties of $\mathrm{Hg}$ atmospheric chemistry, and incomplete RM capture by measurements. Atmospheric chemistry strongly affected the RM / GEM ratio in the atmosphere. The Br chemistry provided the best agreement with observations, reproducing both general levels and seasonal variation of the RM / GEM ratio in the near-surface layer. However, the global distribution of $\mathrm{Br}$ concentration is highly uncertain. Model simulations with the $\mathrm{OH}$ chemical mechanism predicted a shift in maximum $\mathrm{RM} / \mathrm{GEM}$ ratios from spring to summer, but $\mathrm{O}_{3-}$ initiated chemistry did not predict significant seasonal variations in $\mathrm{Hg}$ oxidation.

Wet deposition maps simulated by different models had similar spatial distributions, reflecting the influence of global precipitation patterns and the location of major emission regions. High deposition fluxes are characteristic of Asia, Europe, and North America, where regions with significant anthropogenic sources and intensive precipitation are located. The models agreed relatively well with available long-term $\mathrm{Hg}$ wet deposition observations. The model-to-measurement deviations commonly did not exceed a factor of 2 . However, there was a tendency to overpredict low deposition fluxes measured in Asia and in the Southern Hemisphere. Similarly to RM concentrations, wet deposition of $\mathrm{Hg}$ in background regions is strongly determined by atmospheric oxidation chemistry. Model runs with the $\mathrm{Br}$ oxidation mechanism predicted a wet deposition maximum in spring, instead of in summer as observed at monitoring sites in North America and Europe. $\mathrm{O}_{3}$ chemistry did not predict significant seasonal changes of wet deposition flux in these regions. Use of $\mathrm{OH}$ chemistry enabled reproduction of both the periods of max- 
imum and minimum values and the amplitude of observed seasonal variations.

Hence, the performance of the $\mathrm{Hg}$ oxidation mechanisms studied differed in the quality of their reproduction of the various observed parameters, which can imply the possibility of more complex chemistry and multiple $\mathrm{Hg}$ oxidation pathways occurring concurrently in various parts of the atmosphere. More extensive measurements of atmospheric RM (including identification of $\mathrm{Hg}$ chemical species) and wet deposition are needed in various geographic regions and under different climatic conditions to achieve further improvement of $\mathrm{Hg}$ chemical transport models.

Data availability. Mercury modeling and measurement data discussed in this paper are reported within the GMOS central database and are available upon request at http://sdi.iia.cnr.it/geoint/ publicpage/GMOS.

\section{The Supplement related to this article is available online at doi:10.5194/acp-17-5271-2017-supplement.}

Author contributions. The names after the first author in the above list are in alphabetical order and all authors have made significant contribution. In particular, H. Angot, P. Artaxo, M. Bencardino, F. D'Amore, M. C. Diéguez, A. Dommergue, R. Ebinghaus, X. B. Feng, O. Magand, L. Martin, N. Mashyanov, N. Pirrone, R. Ramachandran, K. A. Read, F. Sena, F. Sprovieri, D. Wip and I. Wängberg contributed to measurements; J. Bieser, A. Dastoor, F. De Simone, C. N. Gencarelli, I. M. Hedgecock, V. Matthias, A. Ryjkov, N. E. Selin, S. Song, O. Travnikov, and X. Yang contributed to modeling.

Competing interests. The authors declare that they have no conflict of interest.

Acknowledgements. The authors wish to thank David Gay from the National Atmospheric Deposition Program (NADP) and the principal investigators for the AMNet sites (E. Edgerton, W. Luke, J. Chaffin, R. Callison, B. Call, M. Pendleton, E. Miller, and M. Allen) for providing the $\mathrm{Hg}$ measured data used in this study. The authors also gratefully acknowledge the Canadian Air and Precipitation Monitoring Network (CAPMoN) for the data and the National Atmospheric Chemistry (NAtChem) Database and Analysis Facility of Environment Canada (www.ec.gc.ca/natchem) for internet provision of the data. This study was financially supported in part by the EU FP7-ENV-2010 project, "Global Mercury Observation System" (GMOS, grant agreement no. 265113). Noelle E. Selin and Shaojie Song also acknowledge the US National Science Foundation Atmospheric Chemistry Program (grant no. 1053648) for their financial support. Aurélien Dommergue and Olivier Magand acknowledge the French Polar Institute, IPEV (GMOstral 1028), for funding and logistics.
Edited by: C. Barbante

Reviewed by: two anonymous referees

\section{References}

AMAP/UNEP, Technical Background Report for the Global Mercury Assessment 2013a. Arctic Monitoring and Assessment Programme, Oslo, Norway / UNEP Chemicals Branch, Geneva, Switzerland, vi +263 pp., available at: http://www.amap.no/ documents/download/1265 (last access: 10 April 2017), 2013.

AMAP/UNEP, Geospatially distributed mercury emissions dataset 2010v1, available at: http://www.amap.no/mercury-emissions (last access: 1 August 2016), 2013b.

AMAP/UNEP, Global Mercury Modelling: Update of Modelling Results in the Global Mercury Assessment 2013. Arctic Monitoring and Assessment Programme, Oslo, Norway/UNEP Chemicals Branch, Geneva, Switzerland. iv + 32 pp., available at: http://www.unep.org/chemicalsandwaste/Mercury/ ReportsandPublications/tabid/3593/Default.aspx (last access: 1 August 2016), 2015.

AMNet: Atmospheric Mercury Network, available at: http://nadp. sws.uiuc.edu/amn/, last access: 1 August 2016.

Amos, H. M., Jacob, D. J., Holmes, C. D., Fisher, J. A., Wang, Q., Yantosca, R. M., Corbitt, E. S., Galarneau, E., Rutter, A. P., Gustin, M. S., Steffen, A., Schauer, J. J., Graydon, J. A., Louis, V. L. St., Talbot, R. W., Edgerton, E. S., Zhang, Y., and Sunderland, E. M.: Gas-particle partitioning of atmospheric $\mathrm{Hg}$ (II) and its effect on global mercury deposition, Atmos. Chem. Phys., 12, 591-603, doi:10.5194/acp-12-591-2012, 201

Angálil, O., Perkins-Kirkpatrick, S., Alexander, L. V., Stone, D., Donat, M. G., Wehner, M., Shiogama, H., Ciavarella, A., Christidis, N.: Comparing regional precipitation and temperature extremes in climate model and reanalysis products, Weather and Climate Extremes, 13, 35-43, doi:10.1016/j.wace.2016.07.001, 2016.

Angot, H., Dastoor, A., De Simone, F., Gårdfeldt, K., Gencarelli, C. N., Hedgecock, I. M., Langer, S., Magand, O., Mastromonaco, M. N., Nordstrøm, C., Pfaffhuber, K. A., Pirrone, N., Ryjkov, A., Selin, N. E., Skov, H., Song, S., Sprovieri, F., Steffen, A., Toyota, K., Travnikov, O., Yang, X., and Dommergue, A.: Chemical cycling and deposition of atmospheric mercury in polar regions: review of recent measurements and comparison with models, Atmos. Chem. Phys., 16, 10735-10763, doi:10.5194/acp-1610735-2016, 2016.

Ariya, P. A., Amyot, M., Dastoor, A., Deeds, D., Feinberg, A., Kos, G., Poulain, A., Ryjkov, A., Semeniuk, K., Subir, M., and Toyota, K.: Mercury Physicochemical and Biogeochemical Transformation in the Atmosphere and at Atmospheric Interfaces: A Review and Future Directions, Chem. Rev., 15, 3760-3802, doi:10.1021/cr500667e, 2015.

Baker, K. R. and Bash, J. O.: Regional Scale Photochemical Model Evaluation of Total Mercury Wet Deposition and Speciated Ambient Mercury, Atmos. Environ., 49, 151-162, 2012.

Balabanov, N., Shepler, B., Peterson, K.: Accurate global potential energy surface and reaction dynamics for the ground state of $\mathrm{HgBr}_{2}$, J. Phys. Chem. A, 109, 8765-8773, 2005.

Bey, I., Jacob, D. J., Yantosca, R. M., Logan, J. A., Field, B. D., Fiore, A. M., Li, Q., Liu, H. Y., Mickley, L. J., and Schultz, M. 
G.: Global modeling of tropospheric chemistry with assimilated meteorology: Model description and evaluation, J. Geophys. Res.-Atmos., 106, 23073-23095, doi:10.1029/2001jd000807, 2001.

Bieser, J., De Simone, F., Gencarelli, C., Geyer, B., Hedgecock, I., Matthias, V., Travnikov, O., and Weigelt, A.: A diagnostic evaluation of modeled mercury wet depositions in Europe using atmospheric speciated high-resolution observations, Environ. Sci. Pollut. R., 21, 9995-10012, doi:10.1007/s11356-014-28632, 2014.

Calvert, J. G. and Lindberg, S. E.: Mechanisms of mercury removal by $\mathrm{O}_{3}$ and $\mathrm{OH}$ in the atmosphere, Atmos. Environ., 39, 33553367, doi:10.1016/j.atmosenv.2005.01.055, 2005.

Choi, H.-D., Sharac, T. J., and Holsen, T. M.: Mercury deposition in the Adirondacks: A comparison between precipitation and throughfall, Atmos. Environ., 42, 1818-1827, 2008.

Christensen, J. H., Brandt, J., Frohn, L. M., and Skov, H.: Modelling of Mercury in the Arctic with the Danish Eulerian Hemispheric Model, Atmos. Chem. Phys., 4, 2251-2257, doi:10.5194/acp-42251-2004, 2004.

Clever, H. L., Johnson, S. A., and Derrick, M. E.: The solubility of mercury and some sparingly soluble mercury salts in water and aqueous electrolyte solutions, J. Phys. Chem. Ref. Data, 14, 631-680, 1985

Cole, A. S., Steffen, A., Pfaffhuber, K. A., Berg, T., Pilote, M., Poissant, L., Tordon, R., and Hung, H.: Ten-year trends of atmospheric mercury in the high Arctic compared to Canadian subArctic and mid-latitude sites, Atmos. Chem. Phys., 13, 15351545, doi:10.5194/acp-13-1535-2013, 2013.

Cohen, M. D., Draxler, R. R., Artz, R. S., Gustin, M., Han, Y.-J., Holsen, T. M., Jaffe, D., Kelley, P., Lei, H., Loughner, C., Luke, W., Lyman, S., Niemi, D. Pacyna, J. M., Pilote, M., Poissant, L., Ratte, D., Ren, X., Steenhouisen, F., Tordon, R., and Wilson, S.: Modeling the global atmospheric transport and deposition of mercury to the Great Lakes, Elementa: Science of the Anthropocene, 4, 000118, doi:10.12952journal.elementa.999118, 2016.

Cremer, D., Kraka, E., and Filatov, M.: Bonding in Mercury Molecules Described by the Normalized Elimination of the Small Component and Coupled Cluster Theory, Chem. Phys. Chem., 9, 2510-2521, doi:10.1002/cphc.200800510, 2008.

Dastoor, A. P. and Larocque, Y.: Global circulation of atmospheric mercury: a modelling study, Atmos. Environ., 38, 147-161, 2004.

Dastoor, A. P., Davignon, D., Theys, N., Van Roozendael, M., Steffen, A., and Ariya, P. A.: Modeling dynamic exchange of gaseous elemental mercury at polar sunrise, Environ. Sci. Technol., 42, 5183-5188, 2008.

Dastoor, A., Ryzhkov, A., Durnford, D., Lehnherr, I., Steffen, A., and Morrison, H.: Atmospheric mercury in the Canadian Arctic. Part II: Insight from modeling, Sci. Total Environ., 509-510, 1627, doi:10.1016/j.scitotenv.2014.10.112, 2015

De Simone, F., Gencarelli, C. N., Hedgecock, I. M., and Pirrone, N.: Global atmospheric cycle of mercury: a model study on the impact of oxidation mechanisms, Environ. Sci. Pollut. R., 21, 4110 4123, 2014.

De Simone, F., Cinnirella, S., Gencarelli, C. N., Yang, X., Hedgecock, I. M., and Pirrone, N.: Model study of global mercury deposition from biomass burning, Environ. Sci. Technol., 49, 6712$6721,2015$.
De Simone, F., Artaxo, P., Bencardino, M., Cinnirella, S., Carbone, F., D’Amore, F., Dommergue, A., Feng, X. B., Gencarelli, C. N., Hedgecock, I. M., Landis, M. S., Sprovieri, F., Suzuki, N., Wängberg, I., and Pirrone, N.: Particulate-phase mercury emissions from biomass burning and impact on resulting deposition: a modelling assessment, Atmos. Chem. Phys., 17, 1881-1899, doi:10.5194/acp-17-1881-2017, 2017.

Dibble, T. S., Zelie, M. J., and Mao, H.: Thermodynamics of reactions of $\mathrm{ClHg}$ and $\mathrm{BrHg}$ radicals with atmospherically abundant free radicals, Atmos. Chem. Phys., 12, 10271-10279, doi:10.5194/acp-12-10271-2012, 2012.

Donohoue, D. L., Bauer, D., Cossairt, B., and Hynes, A. J.: Temperature and Pressure Dependent Rate Coefficients for the Reaction of $\mathrm{Hg}$ with $\mathrm{Br}$ and the Reaction of $\mathrm{Br}$ with $\mathrm{Br}$ : A Pulsed Laser Photolysis-Pulsed Laser Induced Fluorescence Study, J. Phys. Chem. A, 110, 6623-6632, doi:10.1021/jp054688j, 2006.

Durnford, D., Dastoor, A., Figueras-Nieto, D., and Ryjkov, A.: Long range transport of mercury to the Arctic and across Canada, Atmos. Chem. Phys., 10, 6063-6086, doi:10.5194/acp-10-60632010, 2010.

Durnford, D., Dastoor, A., Ryzhkov, A., Poissant, L., Pilote, M., and Figueras-Nieto, D.: How relevant is the deposition of mercury onto snowpacks? - Part 2: A modeling study, Atmos. Chem. Phys., 12, 9251-9274, doi:10.5194/acp-12-9251-2012, 2012.

ECMWF: European Centre for Medium-Range Weather Forecasts, available at http://www.ecmwf.int/en/forecasts/datasets, last access: 10 April 2017.

EMEP: The European Monitoring and Evaluation Programme, EBAS database, available at: http://ebas.nilu.no/Default.aspx, last access: 1 August 2016.

Emmons, L. K., Walters, S., Hess, P. G., Lamarque, J.-F., Pfister, G. G., Fillmore, D., Granier, C., Guenther, A., Kinnison, D., Laepple, T., Orlando, J., Tie, X., Tyndall, G., Wiedinmyer, C., Baughcum, S. L., and Kloster, S.: Description and evaluation of the Model for Ozone and Related chemical Tracers, version 4 (MOZART-4), Geosci. Model Dev., 3, 43-67, doi:10.5194/gmd3-43-2010, 2010.

Fitzgerald, W. F., Engstrom, D. R., Mason, R. P., and Nater, E. A.: The case for atmospheric mercury contamination in remote areas, Environ. Sci. Technol, 32, 1-7, 1998.

Gay, D. A., Schmeltz, D., Prestbo, E., Olson, M., Sharac, T., and Tordon, R.: The Atmospheric Mercury Network: measurement and initial examination of an ongoing atmospheric mercury record across North America, Atmos. Chem. Phys., 13, 1133911349, doi:10.5194/acp-13-11339-2013, 2013.

Gbor, P. K., Wen, D., Meng, F., Yang, F., and Sloan, J. J.: Sloan Modeling of mercury emission, transport and deposition in North America, Atmos. Environ., 41, 1135-1149, 2007.

Gencarelli, C. N., De Simone, F., Hedgecock, I. M., Sprovieri, F., and Pirrone, N.: Development and Application of a RegionalScale Atmospheric Mercury Model Based on WRF/Chem: A Mediterranean Area Investigation. Environ. Sci. Pollut. R., 21, 4095-4109, 2014.

GMOS: Global Mercury Observation System, Spatial Data Infrastructure, available at: http://www.gmos.eu/sdi/, last access: $1 \mathrm{Au}-$ gust 2016.

Goodsite, M. E., Plane, J. M. C., and Skov, H. A Theoretical Study of the Oxidation of $\mathrm{Hg}^{0}$ to $\mathrm{HgBr}_{2}$ in the Troposphere, Environ. Sci. Technol., 38, 1772-1776, 2004. 
Goodsite, M. E., Plane, J. M. C., and Skov, H.: Correction to A Theoretical Study of the Oxidation of $\mathrm{Hg}^{0}$ to $\mathrm{HgBr}_{2}$ in the Troposphere, Environ. Sci. Technol., 46, 5262, doi:10.1021/es301201c, 2012.

Granier, C., Lamarque, J., Mieville, A., Muller, J., Olivier, J., Orlando, J., Peters, J., Petron, G., Tyndall, G., and Wallens, S.: POET, a database of surface emissions of ozone precursors, available at: http://www.aero.jussieu.fr/projet/ACCENT/POET. php (last access: 1 August 2016), 2005.

Gratz, L. E., Ambrose, J. L., Jaffe, D. A., Shah, V., Jaeglé, L., Stutz, J., Festa, J., Spolaor, M., Tsai, C., Selin, N. E., Song, S., Zhou, X., Weinheimer, A. J., Knapp, D. J., Montzka, D. D., Flocke, F. M., Campos, T. L., Apel, E., Hornbrook, R., Blake, N. J., Hall, S., Tyndall, G. S., Reeves, M., Stechman, D., and Stell, M.: Oxidation of mercury by bromine in the subtropical Pacific free troposphere, Geophys. Res. Lett., 42, 10494-10502, 2015.

Guentzel, J. L., Landing, W. M., Gill, G. A., and Pollman, C. D.: Processes Influencing Rainfall Deposition of Mercury in Florida, Environ. Sci. Technol., 35, 863-873, 2001.

Gustin, M. S.: Exchange of Mercury between the Atmosphere and Terrestrial Ecosystems, in: Environmental Chemistry and Toxicology of Mercury, edited by: Liu, G., Cai, Y., and O'Driscoll, N., John Wiley \& Sons, Inc., Hoboken, NJ, USA, 423-451, doi:10.1002/9781118146644.ch13, 2012.

Gustin, M., Weiss-Penzias, P. S., and Peterson, C.: Investigating sources of gaseous oxidized mercury in dry deposition at three sites across Florida, USA, Atmos. Chem. Phys., 12, 9201-9219, doi:10.5194/acp-12-9201-2012, 2012.

Gustin, M. S., Huang, J., Miller, M. B., Finley, B. D., Call, K., Ambrose, J. L., Peterson, C., Lyman, S. N., Everhart, S., Bauer, D., Remeika, J., Hynes, A., Jaffe, D. A., and Lindberg, S. E.: RAMIX - a step towards understanding mercury atmospheric chemistry and Tekran ${ }^{\circledR}$ observations, Environ. Sci. Technol., 47, 7295-7306, 2013.

Gustin, M. S., Amos, H. M., Huang, J., Miller, M. B., and Heidecorn, K.: Measuring and modeling mercury in the atmosphere: a critical review, Atmos. Chem. Phys., 15, 5697-5713, doi:10.5194/acp-15-5697-2015, 2015.

Hall, B.: The gas phase oxidation of mercury by ozone, Water Air Soil Poll., 80, 301-315, 1995.

Hedgecock, I. M. and Pirrone, N.: Chasing quicksilver: Modeling the atmospheric lifetime of $\mathrm{Hg}-(\mathrm{g})(0)$ in the marine boundary layer at various latitudes, Environ. Sci. Technol., 38, 69-76, 2004.

Holmes, C. D., Jacob D. J., Mason R. P., and Jaffe D. A.: Sources and deposition of reactive gaseous mercury in the marine atmosphere, Atmos. Environ., 43, 2278-2285, 2009.

Holmes, C. D., Jacob, D. J., Corbitt, E. S., Mao, J., Yang, X., Talbot, R., and Slemr, F.: Global atmospheric model for mercury including oxidation by bromine atoms, Atmos. Chem. Phys., 10, 12037-12057, doi:10.5194/acp-10-12037-2010, 2010.

Horowitz, H. M., Jacob, D. J., Zhang, Y., Dibble, T. S., Slemr, F., Amos, H. M., Schmidt, J. A., Corbitt, E. S., Marais, E. A., and Sunderland, E. M.: A new mechanism for atmospheric mercury redox chemistry: Implications for the global mercury budget, Atmos. Chem. Phys. Discuss., doi:10.5194/acp-2016-1165, in review, 2017.
Huang, J. and Gustin, M. S.: Impacts of relative humidity on GOM measurements, Environ. Sci. Technol., 49, 6102-6108, doi:10.1021/acs.est.5b00098, 2015.

Hynes, A. J., Donohoue, D. L., Goodsite, M. E., and Hedgecock, I. M.: Our current understanding of major chemical and physical processes affecting mercury dynamics in the atmosphere and at the air-water/terrestrial interfaces, in: Mercury Fate and Transport in the Global Atmosphere, edited by: Mason, R. and Pirrone, N., Springer, New York, 427-457, 2009.

Jung, G., Hedgecock, I. M., and Pirrone, N.: ECHMERIT V1.0 - a new global fully coupled mercury-chemistry and transport model, Geosci. Model Dev., 2, 175-195, doi:10.5194/gmd-2175-2009, 2009.

Keeler, G., Gratz, L., and Al-wali, K.: Long-term Atmospheric Mercury Wet Deposition at Underhill, Vermont, Ecotoxicology, 14, 71-83, 2005.

Kos, G., Ryzhkov, A., Dastoor, A., Narayan, J., Steffen, A., Ariya, P. A., and Zhang, L.: Evaluation of discrepancy between measured and modelled oxidized mercury species, Atmos. Chem. Phys., 13, 4839-4863, doi:10.5194/acp-13-4839-2013, 2013.

Krabbenhoft, D. P. and Sunderland, E. M.: Global change and mercury, Science, 341, 1457-1458, 2013.

Lan, X., Talbot, R., Castro, M., Perry, K., and Luke, W.: Seasonal and diurnal variations of atmospheric mercury across the US determined from AMNet monitoring data, Atmos. Chem. Phys., 12, 10569-10582, doi:10.5194/acp-12-10569-2012, 2012.

Lin, C.-J., Pongprueksa, P., Lindberg, S. E., Pehkonen, S. O., Byun, D., and Jang, C.: Scientific uncertainties in atmospheric mercury models I: Model science evaluation, Atmos. Environ., 40, 29112928, 2006.

Lindberg, S. E. and Stratton, W. J.: Atmospheric mercury speciation: concentrations and behavior of reactive gaseous mercury in ambient air, Environ. Sci. Technol., 32, 49-57, 1998.

Lohman, K., Seigneur, C., Gustin, M., and Lindberg, S.: Sensitivity of the global atmospheric cycle of mercury to emissions, Appl. Geochem., 23, 454-466, 2008.

Lyman, S. N. and Jaffe, D. A.: Formation and fate of oxidized mercury in the upper troposphere and lower stratosphere, Nat. Geosci., 5, 114-117, 2011.

Lyman, S. N., Jaffe, D. A., and Gustin, M. S.: Release of mercury halides from $\mathrm{KCl}$ denuders in the presence of ozone, Atmos. Chem. Phys., 10, 8197-8204, doi:10.5194/acp-10-81972010, 2010.

Mahaffey, K. R., Clickner, R. P., and Bodurow, C. C.: Blood organic mercury and dietary mercury intake: National Health and Nutrition Examination Survey, 1999 and 2000, Environ. Health Persp., 112, 562-670, 2004.

Mason, R.: Mercury emissions from natural processes and their importance in the global mercury cycle, in: Mercury fate and transport in the global atmosphere, in: Mercury Fate and Transport in the Global Atmosphere: Emissions, Measurements, and Models, edited by: Pirrone, N. and Mason, R. P., Springer, 173-191, 2009.

Mason, R. P. and Sheu, G. R.: Role of the ocean in the global mercury cycle, Global Biogeochem. Cy., 16, 1093, doi:10.1029/2001GB001440, 2002.

Mason, R. P., Choi, A. L., Fitzgerald, W. F., Hammerschmidt, C. R., Lamborg, C. H., Soerensen, A. L., and Sunderland, E. M.: 
Mercury biogeochemical cycling in the ocean and policy implications, Environ. Res., 119, 101-117, 2012.

Munthe, J.: The aqueous oxidation of elemental mercury by ozone, Atmos. Environ., 26, 1461-1468, 1992.

Nair, U. S., Wu, Y., Walters, J., Jansen, J., Edgerton, E. S.: Diurnal and seasonal variation of mercury species at coastal suburban, urban, and rural sites in the southeastern United States, Atmos. Environ., 47, 499-508, 2012.

NADP/MDN: National Atmospheric Deposition Program (NRSP3), Mercury Deposition Network (MDN), NADP Program Office, Illinois State Water Survey, 2204 Griffith Dr., Champaign, IL 61820, available at: http://nadp.sws.uiuc.edu/MDN/, access: 1 August 2016.

NAtChem: The Canadian National Atmospheric Chemistry Database And Analysis System, available at: http://www.ec.gc. ca/natchem/, last access: 1 August 2016.

Obrist, D., Tas, E., Peleg, M., Matveev, V., Faïn, X., Asaf, D., and Luria, M.: Bromine-induced oxidation of mercury in the midlatitude atmosphere, Nat. Geosci., 4, 22-26, 2011.

Pan, L., Lin, C.-J., Carmichael, G. R., Streets, D. G., Tang, Y., Woo, J.-H., Shetty, S. K., Chu, H.-W., Ho, T. C., and Friedli, H. R.: Study of Atmospheric Mercury Budget in East Asia Using STEM-Hg Modeling System, Sci. Total Environ., 408, $3277-$ 3291,2010

Parrella, J. P., Jacob, D. J., Liang, Q., Zhang, Y., Mickley, L. J., Miller, B., Evans, M. J., Yang, X., Pyle, J. A., Theys, N., and Van Roozendael, M.: Tropospheric bromine chemistry: implications for present and pre-industrial ozone and mercury, Atmos. Chem. Phys., 12, 6723-6740, doi:10.5194/acp-12-6723-2012, 2012.

Peters, J. A. H. W. and Olivier, J. G. J.: EDGAR3/POET ENUSSUIBS; 1997 emissions and scenarios for 1995-2020; technical background information on global and regional sectoral emissions, Report no. 773301003, RIVM, Bilthoven, 2003.

Pirrone, N., Cinnirella, S., Feng, X., Finkelman, R. B., Friedli, H. R., Leaner, J., Mason, R., Mukherjee, A. B., Stracher, G. B., Streets, D. G., and Telmer, K.: Global mercury emissions to the atmosphere from anthropogenic and natural sources, Atmos. Chem. Phys., 10, 5951-5964, doi:10.5194/acp-10-59512010, 2010

Platt, U. and Janssen, C.: Observation and role of the free radicals $\mathrm{NO}_{3}, \mathrm{ClO}, \mathrm{BrO}$ and $\mathrm{IO}$ in the troposphere, Faraday Discuss., 100, 175-198, 1995.

Poissant, L., Pilote, M., Beauvais, C., Constant, P., and Zhang, H. H.: A year of continuous measurements of three atmospheric mercury species (GEM, RGM and Hgp) in southern Quebec, Canada, Atmos. Environ., 39, 1275-1287, doi:10.1016/j.atmosenv.2004.11.007, 2005.

Prestbo, E. M. and Gay, D. A.: Wet deposition of mercury in the U.S. and Canada, 1996-2005: Results and analysis of the NADP mercury deposition network (MDN), Atmos. Environ., 43, 42234233, 2009.

Qureshi, A., Macleod, M., Sunderland, E., and Hungerbühler, K.: Exchange of elemental mercury between the oceans and the atmosphere, in: Environmental Chemistry and Toxicology of Mercury, edited by: Liu, G., Cai, Y., and O'Driscoll, N., John Wiley \& Sons, Inc., Hoboken, NJ, USA, 389-421, doi:10.1002/9781118146644.ch12, 2012.
Rutter, A. P., Shakya, K. M., Lehr, R., Schauer, J. J., and Griffin, R. J.: Oxidation of gaseous elemental mercury in the presence of secondary organic aerosols, Atmos. Environ., 59, 86-92, 2012.

Sather, M. E., Mukerjee, S., Smith, L., Mathew, J., Jackson, C., Callison, R., Scrapper, L., Hathcoat, A., Adam, J., Keese, D., Ketcher, P., Brunette, R., Calstrom, J., and Van der Jagt, G.: Gaseous oxidized mercury dry deposition measurements in the Four Corners Area and Eastern Oklahoma, USA, Atmos. Pollut. Res., 4, 168-180, 2013.

Schroeder, W. H. and Munthe, J.: Atmospheric mercury - an overview, Atmos. Environ., 32, 809-822, 1998.

Seigneur, C. and Lohman, K.: Effect of bromine chemistry on the atmospheric mercury cycle, J. Geophys. Res., 113, D23309, doi:10.1029/2008JD010262, 2008.

Seigneur, C., Karamchandani, P., Lohman, K., Vijayaraghavan, K., and Shia, R.-L.: Multiscale modeling of the atmospheric fate and transport of mercury, J. Geophys. Res., 106, 27795-27809, 2001.

Seigneur, C., Vijayaraghavan, K., and Lohman, K.: Atmospheric mercury chemistry: Sensitivity of global model simulations to chemical reactions, J. Geophys. Res., 111, D22306, doi:10.1029/2005JD006780, 2006

Selin, N. E.: Global biogeochemical cycling of mercury: A review, Annu. Rev. Env. Resour., 34, 43-63, 2009.

Selin, N. E. and Jacob, D. J.: Seasonal and spatial patterns of mercury wet deposition in the United States: Constraints on the contribution from North American anthropogenic sources, Atmos. Environ., 42, 5193-5204, doi:10.1016/j.atmosenv.2008.02.069, 2008.

Selin, N. E., Jacob, D. J., Yantosca, R. M., Strode, S., Jaeglé, L., and Sunderland, E. M.: Global 3-D land-ocean-atmosphere model for mercury: present-day versus preindustrial cycles and anthropogenic enrichment factors for deposition, Global Biogeochem. Cy., 22, GB2011, doi:10.1029/2007GB003040, 2008.

Shah, V., Jaeglé, L., Gratz, L. E., Ambrose, J. L., Jaffe, D. A., Selin, N. E., Song, S., Campos, T. L., Flocke, F. M., Reeves, M., Stechman, D., Stell, M., Festa, J., Stutz, J., Weinheimer, A. J., Knapp, D. J., Montzka, D. D., Tyndall, G. S., Apel, E. C., Hornbrook, R. S., Hills, A. J., Riemer, D. D., Blake, N. J., Cantrell, C. A., and Mauldin III, R. L.: Origin of oxidized mercury in the summertime free troposphere over the southeastern US, Atmos. Chem. Phys., 16, 1511-1530, doi:10.5194/acp-16-1511-2016, 2016.

Shetty, S. K., Lin, C.-J., Streets, D. G., and Jang, C.: Model estimate of mercury emission from natural sources in East Asia, Atmos. Environ., 42, 8674-8685, 2008.

Sigler, J. M., Mao, H., and Talbot, R.: Gaseous elemental and reactive mercury in Southern New Hampshire, Atmos. Chem. Phys., 9, 1929-1942, doi:10.5194/acp-9-1929-2009, 2009.

Skamarock, W. C., Klemp, J. B., Dudhia, J., Gill, D. O., Barker, D. M., Wang, W., and Powers, J. G.: A description of the Advanced Research WRF Version 2. NCAR/TN-468+STR., NCAR Technical Note, Boulder, CO, USA, 2007.

Slemr, F., Angot, H., Dommergue, A., Magand, O., Barret, M., Weigelt, A., Ebinghaus, R., Brunke, E.-G., Pfaffhuber, K. A., Edwards, G., Howard, D., Powell, J., Keywood, M., and Wang, F.: Comparison of mercury concentrations measured at several sites in the Southern Hemisphere, Atmos. Chem. Phys., 15, 3125 3133, doi:10.5194/acp-15-3125-2015, 2015.

Snider, G., Raofie, F., and Ariya, P. A. A.: Effects of relative humidity and $\mathrm{CO}(\mathrm{g})$ on the $\mathrm{O}_{3}$-initiated oxidation reaction of $\mathrm{HgO}(\mathrm{g})$ : 
Kinetic \& product studies, Phys. Chem. Chem. Phys., 10, 56165623, doi:10.1039/B801226A, 2008.

Soerensen, A. L., Sunderland, E. M., Holmes, C. D., Jacob, D. J., Yantosca, R. M., Skov, H., Christensen, J. H., Strode, S. A., and Mason, R. P.: An improved global model for air-sea exchange of mercury: high concentrations over the north atlantic, Environ. Sci. Technol., 44, 8574-8580, 2010.

Sommar, J., Gårdfeldt, K., Strömberg, D., and Feng, X.: A kinetic study of the gas-phase reaction between the hydroxyl radical and atomic mercury, Atmos. Environ., 35, 3049-3054, 2001.

Song, S., Selin, N. E., Soerensen, A. L., Angot, H., Artz, R., Brooks, S., Brunke, E.-G., Conley, G., Dommergue, A., Ebinghaus, R., Holsen, T. M., Jaffe, D. A., Kang, S., Kelley, P., Luke, W. T., Magand, O., Marumoto, K., Pfaffhuber, K. A., Ren, X., Sheu, G.-R., Slemr, F., Warneke, T., Weigelt, A., Weiss-Penzias, P., Wip, D. C., and Zhang, Q.: Top-down constraints on atmospheric mercury emissions and implications for global biogeochemical cycling, Atmos. Chem. Phys., 15, 7103-7125, doi:10.5194/acp-157103-2015, 2015.

Sprovieri, F., Pirrone, N., Bencardino, M., D'Amore, F., Carbone, F., Cinnirella, S., Mannarino, V., Landis, M., Ebinghaus, R., Weigelt, A., Brunke, E.-G., Labuschagne, C., Martin, L., Munthe, J., Wängberg, I., Artaxo, P., Morais, F., Barbosa, H. D. M. J., Brito, J., Cairns, W., Barbante, C., Diéguez, M. D. C., Garcia, P. E., Dommergue, A., Angot, H., Magand, O., Skov, H., Horvat, M., Kotnik, J., Read, K. A., Neves, L. M., Gawlik, B. M., Sena, F., Mashyanov, N., Obolkin, V., Wip, D., Feng, X. B., Zhang, H., Fu, X., Ramachandran, R., Cossa, D., Knoery, J., Marusczak, N., Nerentorp, M., and Norstrom, C.: Atmospheric mercury concentrations observed at ground-based monitoring sites globally distributed in the framework of the GMOS network, Atmos. Chem. Phys., 16, 11915-11935, doi:10.5194/acp16-11915-2016, 2016.

Sprovieri, F., Pirrone, N., Bencardino, M., D’Amore, F., Angot, H., Barbante, C., Brunke, E.-G., Arcega-Cabrera, F., Cairns, W., Comero, S., Diéguez, M. D. C., Dommergue, A., Ebinghaus, R., Feng, X. B., Fu, X., Garcia, P. E., Gawlik, B. M., Hageström, U., Hansson, K., Horvat, M., Kotnik, J., Labuschagne, C., Magand, O., Martin, L., Mashyanov, N., Mkololo, T., Munthe, J., Obolkin, V., Ramirez Islas, M., Sena, F., Somerset, V., Spandow, P., Vardè, M., Walters, C., Wängberg, I., Weigelt, A., Yang, X., and Zhang, H.: Five-year records of mercury wet deposition flux at GMOS sites in the Northern and Southern hemispheres, Atmos. Chem. Phys., 17, 2689-2708, doi:10.5194/acp-17-2689-2017, 2017.

Steffen A., Lehnherr I., Cole A., Ariya P., Dastoor A., Durnford D., Kirk J., and Pilote M.: Atmospheric mercury in the Canadian Arctic. Part I: A review of recent field measurements, Sci. Total Environ., 509-510, 3-15, doi:10.1016/j.scitotenv.2014.10.109, 2015.

Subir, M., Ariya, P. A., and Dastoor, A. P.: A review of uncertainties in atmospheric modeling of mercury chemistry I. Uncertainties in existing kinetic parameters - Fundamental limitations and the importance of heterogeneous chemistry, Atmos. Environ., 45, 5664-5676, 2011.

Subir, M., Ariya, P. A., and Dastoor, A. P.: A review of the sources of uncertainties in atmospheric mercury modeling II. Mercury surface and heterogeneous chemistry - A missing link, Atmos. Environ., 46, 1-10, 2012.
Sunderland, E., Corbitt, E., Cossa, D., Evers, D., Friedli, H., Krabbenhoft, D., Levin, L., Pirrone, N., and Rice, G.: Impacts of Intercontinental Mercury Transport on Human \& Ecological Health, in: Pirrone, N. and T. Keating, Hemispheric Transport of Air Pollution 2010, Part B: Mercury, Air Pollution Studies No. 16. United Nations, 97-144, 2010.

Swartzendruber, P. and Jaffe, D.: Sources and Transport: A Global Issue, in: Mercury in the environment, edited by: Bank, M. S., University of California Press, Berkeley and Los Angeles, California, 2012.

Tørseth, K., Aas, W., Breivik, K., Fjæraa, A. M., Fiebig, M., Hjellbrekke, A. G., Lund Myhre, C., Solberg, S., and Yttri, K. E.: Introduction to the European Monitoring and Evaluation Programme (EMEP) and observed atmospheric composition change during 1972-2009, Atmos. Chem. Phys., 12, 5447-5481, doi:10.5194/acp-12-5447-2012, 2012.

Tossell, J. A.: Calculation of the energetics for oxidation of gasphase elemental $\mathrm{Hg}$ by $\mathrm{Br}$ and $\mathrm{BrO}$, J. Phys. Chem. A, 107, 7804-7808, 2003.

Travnikov, O.: Contribution of the intercontinental atmospheric transport to mercury pollution in the Northern Hemispherem Atmos. Environ., 39, 7541-7548, 2005.

Travnikov, O.: Atmospheric transport of mercury, in: Environmental Chemistry and Toxicology of Mercury, edited by: Liu, G., Cai, Y., and O'Driscoll, N., John Wiley \& Sons, Inc., Hoboken, NJ, USA, 331-365, doi:10.1002/9781118146644.ch10, 2012.

Travnikov, O. and Ilyin, I.: The EMEP/MSC-E Mercury Modeling System, in: Mercury Fate and Transport in the Global Atmosphere: Emissions, Measurements, and Models, edited by: Pirrone, N. and Mason, R. P., Springer, 571-587, 2009.

Travnikov, O., Jonson, J. E., Andersen, A. S., Gauss, M., Gusev A., Rozovskaya O., Simpson D., Sokovyh V., Valiyaveetil, S., and Wind, P.: Development of the EMEP global modelling framework: Progress report, EMEP/MSC-E Technical Report 7/2009, Meteorological Synthesizing Centre - East of EMEP, Moscow, 44 pp., available at: http://www.msceast.org/index.php/ publications/reports (last access: 10 April 2017), 2009.

Travnikov, O., Lin C. J., Dastoor, A., Bullock, O. R., Hedgecock, I., Holmes, C., Ilyin, I., Jaegle, L., Jung, G., Pan, L., Pongprueksa, P., Ryzhkov, A., Seigneur, C., and Skov, H.: Global and Regional Modeling, in: Pirrone, N. and T. Keating, Hemispheric Transport of Air Pollution 2010, Part B: Mercury, Air Pollution Studies No. 16. United Nations, 97-144, 2010.

Van Loon, L., Mader, E., and Scott, S. L.: Reduction of the aqueous mercuric ion by sulfite: UV spectrum of $\mathrm{HgSO}_{3}$ and its intramolecular redox reaction, J. Phys. Chem. A, 104, 1621-1626, 2000.

Wang, X., Lin, C.-J., and Feng, X.: Sensitivity analysis of an updated bidirectional air-surface exchange model for elemental mercury vapor, Atmos. Chem. Phys., 14, 6273-6287, doi:10.5194/acp-14-6273-2014, 2014.

Wang, X., Lin, C.-J., Yuan, W., Sommar, J., Zhu, W., and Feng, X.: Emission-dominated gas exchange of elemental mercury vapor over natural surfaces in China, Atmos. Chem. Phys., 16, 1112511143, doi:10.5194/acp-16-11125-2016, 2016.

Weigelt, A., Temme, C., Bieber, E., Schwerin, A., Schuetze, M., Ebinghaus, R., and Kock H. H.: Measurements of atmospheric mercury species at a German rural background site from 2009 
to 2011 - methods and results, Environ. Chem., 10, 102-110, doi:10.1071/EN12107, 2013.

Weiss-Penzias, P., Amos, H. M., Selin, N. E., Gustin, M. S., Jaffe, D. A., Obrist, D., Sheu, G.-R., and Giang, A.: Use of a global model to understand speciated atmospheric mercury observations at five high-elevation sites, Atmos. Chem. Phys., 15, 11611173, doi:10.5194/acp-15-1161-2015, 2015.

Wesely, M. L.: Parameterization of surface resistances to gaseous dry deposition in regional-scale numerical models, Atmos. Environ., 23, 1293-1304, doi:10.1016/0004-6981(89)90153-4, 1989.

Wesely, M. L. and Hicks, B. B.: A review of the current status of knowledge on dry deposition, Atmos. Environ., 34, 2261-2222, 2000.

Wright, G., Miller, M. B., Weiss-Penzias, P., and Gustin, M.: Investigation of mercury deposition and potential sources at six sites from the Pacific Coast to the Great Basin, USA, Sci. Total Environ., 470-471C, 1099-1113, doi:10.1016/j.scitotenv.2013.10.071, 2014.

Yang, X., Cox, R., Warwick, N., Pyle, J., Carver, G., O'Connor, F., and Savage, N.: Tropospheric bromine chemistry and its impacts on ozone: A model study, J. Geophys. Res., 110, D23311, doi:10.1029/2005JD006244, 2005.
Yang, X., Pyle, J. A., Cox, R. A., Theys, N., and Van Roozendael, M.: Snow-sourced bromine and its implications for polar tropospheric ozone, Atmos. Chem. Phys., 10, 7763-7773, doi:10.5194/acp-10-7763-2010, 2010.

Zhang, L.: A size-segregated particle dry deposition scheme for an atmospheric aerosol module, Atmos. Environ., 35, 549-560, doi:10.1016/S1352-2310(00)00326-5, 2001.

Zhang, L., Brook, J. R., and Vet, R.: A revised parameterization for gaseous dry deposition in air-quality models, Atmos. Chem. Phys., 3, 2067-2082, doi:10.5194/acp-3-2067-2003, 2003.

Zhang, L., Wright, L. P., and Blanchard, P. A: Review of Current Knowledge Concerning Dry Deposition of Atmospheric Mercury, Atmos. Environ., 43, 5853-5864, 2009.

Zhang, Y., Jaeglé, L., van Donkelaar, A., Martin, R. V., Holmes, C. D., Amos, H. M., Wang, Q., Talbot, R., Artz, R., Brooks, S., Luke, W., Holsen, T. M., Felton, D., Miller, E. K., Perry, K. D., Schmeltz, D., Steffen, A., Tordon, R., Weiss-Penzias, P., and Zsolway, R.: Nested-grid simulation of mercury over North America, Atmos. Chem. Phys., 12, 6095-6111, doi:10.5194/acp12-6095-2012, 2012. 